\title{
Serum Exosomes and Their miRNA Load-A Potential Biomarker of Lung Cancer
}

\author{
Mateusz Smolarz and Piotr Widlak*(D) \\ Maria Skłodowska-Curie National Research Institute of Oncology, Gliwice Branch, 44-101 Gliwice, Poland; \\ mateusz.smolarz@io.gliwice.pl \\ * Correspondence: piotr.widlak@io.gliwice.pl; Tel.: +48-32-2789672
}

Citation: Smolarz, M.; Widlak, P. Serum Exosomes and Their miRNA Load-A Potential Biomarker of Lung Cancer. Cancers 2021, 13, 1373. https: / / doi.org/10.3390/

cancers13061373

Academic Editor: Fabrizio Bianchi

Received: 24 February 2021

Accepted: 15 March 2021

Published: 18 March 2021

Publisher's Note: MDPI stays neutral with regard to jurisdictional claims in published maps and institutional affiliations.

Copyright: (C) 2021 by the authors. Licensee MDPI, Basel, Switzerland. This article is an open access article distributed under the terms and conditions of the Creative Commons Attribution (CC BY) license (https:// creativecommons.org/licenses/by/ $4.0 /)$.
Simple Summary: Exosomes are an emerging source of cancer biomarkers. Molecular components of serum-derived exosomes have been addressed in several reports in the context of biomarkers for early detection of lung cancer. However, despite the promising results of pilot studies, the clinical applicability of such biomarkers has not been validated yet. In this review, the diagnostic potential of miRNA content of serum-derived exosomes is presented. Moreover, potential target genes and signaling pathways affected by miRNA present in lung cancer signatures are discussed.

\begin{abstract}
Early detection of lung cancer in screening programs is a rational way to reduce mortality associated with this malignancy. Low-dose computed tomography, a diagnostic tool used in lung cancer screening, generates a relatively large number of false-positive results, and its complementation with molecular biomarkers would greatly improve the effectiveness of such programs. Several biomarkers of lung cancer based on different components of blood, including miRNA signatures, were proposed. However, only a few of them have been positively validated in the context of early cancer detection yet, which imposes a constant need for new biomarker candidates. An emerging source of cancer biomarkers are exosomes and other types of extracellular vesicles circulating in body fluids. Hence, different molecular components of serum/plasma-derived exosomes were tested and showed different levels in lung cancer patients and healthy individuals. Several studies focused on the miRNA component of these vesicles. Proposed signatures of exosome miRNA had promising diagnostic value, though none of them have yet been clinically validated. These signatures involved a few dozen miRNA species overall, including a few species that recurred in different signatures. It is worth noting that all these miRNA species have cancer-related functions and have been associated with lung cancer progression. Moreover, a few of them, including known oncomirs miR-17, miR-19, miR-21, and miR-221, appeared in multiple miRNA signatures of lung cancer based on both the whole serum/plasma and serum/plasma-derived exosomes.
\end{abstract}

Keywords: biomarkers; exosome; extracellular vesicles; lung cancer; miRNA; plasma; serum

\section{Introduction}

Lung cancer is among the major cancer-related public health problem responsible for about a quarter of cancer-related deaths worldwide. Overall, the lung cancer five-year survival rate (below 20\%) is much lower than other leading cancer sites, such as colorectal (about 65\%), breast (about 90\%), and prostate (about 95\%). Though the risk and incidence of lung cancer are slightly higher among men, this malignancy is becoming the major cause of cancer-related death also in women. The majority of lung cancer cases are diagnosed at advanced stages and have unfavorable prognoses (the average five-year survival of about $10-15 \%)$. However, in the case of the disease detected at the early stages, the prognosis is much better (the average five-year survival varies between 65 and $85 \%$ ). Thus, in addition to primary prevention (i.e., tobacco smoking control), screening for early detection was proposed as a promising strategy to reduce lung cancer mortality $[1,2]$. Several 
screening tools have been investigated during the past decades, but only one, the low-dose computed tomography (LD-CT), has found an application in clinical practice. Originally, the results of the National Lung Screening Trial (NLST) showed that compared to chest X-ray examination, the LD-CT screening was associated with over $20 \%$ reduction of lung cancer-specific mortality in a high-risk group of subjects defined by their smoking status and age [3]. The potential of LD-CT screening programs to reduce lung cancer mortality was further confirmed by other studies [2], including the Dutch-Belgian NELSON trial [4] and the Danish Lung Cancer Screening Trial (DLCST) [5]. It is estimated that the use of LD-CT allows for earlier detection of lung cancers in about 12,000 people a year, which is about $8 \%$ of deaths annually due to this disease. It is worth noting, however, that LD-CT allows detecting abnormalities in $20-40 \%$ of people undergoing this examination, but as much as $95 \%$ of results could be false-positive [6]. Hence, due to the low specificity of LD-CT (positive predictive value of only $3.8 \%$ in the NLST), the vast majority of patients with screen-detected chest abnormalities are subjected to further expensive and potentially harmful diagnostic procedures, such as transthoracic or bronchoscopic biopsy or surgery. It is estimated that about $75 \%$ of patients unnecessarily underwent diagnostic workup, including $25 \%$ subjected to invasive procedures [7]. Hence, there is an urgent need for clinical and molecular tests supporting CT-based screening for the detection of lung cancer to reduce "over-diagnosis" and decrease the costs. Such test(s) could either pre-select individuals for LD-CT examination or discriminate between benign and malignant chest abnormalities detected by LD-CT [8,9].

Potential biomarkers for early lung cancer can be found in various biological fluids; however, blood is the richest and most readily available source $[10,11]$. Candidates for such biomarkers include serum proteins, free nucleic acids, and metabolites [11,12]. Several works reported serum/plasma proteins, which levels are associated with the risk of lung cancer [13]. Another candidate for the biomarker of lung cancer is circulating free DNA (cfDNA) [14] and circulating tumor cells (CTC) [15]. More recently, serum metabolites and lipids have emerged as another class of potential biomarkers in lung cancer [16,17]. Several other review papers could be suggested that cover this well-researched field [11-13,18-21]. However, though numerous biomarker candidates have been proposed only a few of them have been positively validated in the proper clinical settings. The main reason was the lack of sensitivity and analytical reproducibility, which in turn led to the elimination of potential candidates from further stages of biomarker testing [9,12]. Moreover, none of the tested biomarkers increased the actual number of detected early lung cancer cases yet $[18,20,22]$. Currently, only two molecular tests are used in clinical practice to help in the diagnosis of indeterminate pulmonary nodules detected by CT. One of them is the autoantigen-based EarlyCDT-Lung test, which enables the classification of indeterminate nodules with a positive predictive value (PPV) $>70 \%$ [23]. Another test is the XL2 test, which combines the clinical probability of cancer score with the level of two plasma proteins: LG3BP and C163A [24]. Hence, the identification of the reliable molecular biomarker that could be used for the early detection of lung cancer remains a timely and vital issue.

The purpose of this literature review is to summarize current data on the emerging biomarker of early lung cancer-circulating serum exosomes and their microRNA cargo.

\section{Micro RNA Signatures of Lung Cancer}

In the search for a lung cancer biomarker, there were numerous studies focused on microRNAs (miRNAs). It is a class of small endogenous non-coding RNAs of 18-24 nucleotides responsible for the regulation of target genes. More than 2500 mature miRNAs have been described in humans yet [25-27]. miRNA is transcribed in the cell nucleus with the participation of RNA polymerase II resulting in pri-miRNA, which is processed by the Drosh/DGCR8 enzyme complex to precursor miRNA (pre-miRNA). The resulting pre-miRNA is transported from the nucleus to the cytoplasm involving Exportin-5, where it is processed by Dicer nuclease to form miRNA duplexes or mature miRNA. Usually, a less-thermostable 5'-terminus strand is packed to the protein complex (RISC), whose main component is a protein from the Argonaut 
family (AGO), while the second strand is degraded. The RISC complex then recognizes the target mRNA and binds at the $3^{\prime} \mathrm{UTR}$ position: mRNA degradation occurs in the case of perfect miRNA/mRNA matching, while translation repression in the case of incomplete alignment. Thus, by silencing target mRNAs, miRNAs affect many critical cellular processes such as cell proliferation, apoptosis, differentiation, and metabolism $[27,28]$.

The composition of miRNA component of tissues (so-called miR-ome) could be affected by different pathological conditions; hence, the diagnostic and prognostic values of miRNA signatures have been addressed in many studies [29-34]. miRNA is resistant to RNase digestion, boiling, extended storage, extreme $\mathrm{pH}$, and multiple freezing and thawing cycles [35]. Moreover, miRNA is considered to be more stable than other classes of RNA in blood and other biofluids. However, it should be noted that during the analysis of free circulating miRNA in human blood, miRNA molecules released by cancer cells and other classes of "normal" cells (platelets, red blood cells, and endothelial cells) are co-purified and co-analyzed [36]. Nevertheless, miRNA circulating in the blood and present in the isolated serum (i.e., the liquid fraction of blood remaining after removal of the clot followed coagulation) or plasma (i.e., the liquid fraction of blood remaining after removal of cell components without coagulation), is an emerging source of disease biomarkers including lung cancer.

Several studies addressed circulating miRNA as potential molecular signatures to be used for the diagnosis of lung cancer. Numerous papers have been published since 2011 that described signatures of serum/plasma miRNA, which enabled the differentiation between lung cancer patients and healthy individuals. Some of these reports described single miRNA, yet most of them proposed multi-component panels up to 24 plasma miRNAs [37] or 34 serum miRNAs [38]. Examples of such studies are listed in Table 1. Proposed lung cancer signatures involved about 100 miRNA species overall, which (according to our literature review) included 39 miRNA species that recurred in more than one signature. However, only four miRNA species were included in more than five signatures, namely, miR-21 (11 signatures), miR-148b (8 signatures), miR-126, and miR-486-5p (seven signatures). Hence, the overlap among different signatures was relatively low, which putatively reflected different clinical characteristics of lung cancer patients and their ethnic/genetic backgrounds as well as different analytical approaches used in different studies. Nevertheless, we analyzed a subset of 39 miRNA species that appeared in multiple lung cancer signatures in the search for their target genes and associated biological functions; the bioinformatics tool miRSystem (version 20160513) was used [39]. Among the biological processes associated with this subset of miRNAs and statistically overrepresented, several pathways were involved in cancer development, including the MAPK signaling, FGFR signaling, transport of glucose, apoptosis, and antigen processing/presentation. This subset included several known "oncomirs", exemplified by miR-21, which will be discussed in detail below. Furthermore, among the genes hypothetically targeted by the highest number of miRs from this subset were a few genes with putative cancer-related functions, exemplified by IFI30, PLA2G10, FGF6, ZBTB16, and CORO1A. IFI30 encodes a lysosomal thiol reductase involved in the processing of MHC class II-restricted antigen, which was reported in the development of melanoma [40]. PLA2G10 encodes a phospholipase A2 family member involved in the production of inflammatory lipid mediators (e.g., prostaglandins), which was reported in the progression of breast cancer [41]. FGF6 encodes a fibroblast growth factor (FGF) family member involved in tumor growth [42]. ZBTB16 encodes a Krueppel $\mathrm{C} 2 \mathrm{H} 2$ zinc finger family member involved in the regulation of cell cycle, apoptosis, and the AKT/Foxo3a pathway [43]. CORO1A encodes a WD-repeat protein family member involved in the cell cycle progression, apoptosis, and signal transduction [44]. Hence, cancer-related functions of miRNA species present in the proposed lung cancer signatures provide additional validation of their putative diagnostic importance.

In conclusion, circulating miRNA appears a forward-looking diagnostic tool in the detection of lung cancer. Proposed signatures revealed promising sensitivity and specificity, which usually reached $80-90 \%$. Still, their actual diagnostic reproducibility requires 
further validation and clinical testing [25,35,45-47]. Further, none of the proposed miRNA signatures have yet been conclusively validated in the prospective clinical studies. Nevertheless, three registered clinical trials are currently ongoing that include validation of the serum/plasma miRNA signatures of early lung cancer. The BIOMILD study (NCT02247453) sponsored by the Fondazione IRCCS Istituto Nazionale dei Tumori (Milano) is aimed at the validation of the Plasma miR Signature Classifier [37]. The COSMOS study (NCT01248806) sponsored by the European Institute of Oncology involves validation of the miR-Test [48] in the context of lung cancer screening. Moreover, a smaller study sponsored by Hummingbird Diagnostics (NCT03452514) is aimed at the validation of the commercial HMBDx microRNA Test in a group of participants of the LD-CT lung cancer screening. However, all these clinical trials are still running, and no conclusions are available yet (the planned completion date of these studies is 2021).

Table 1. Examples of serum/plasma miRNAs as biomarkers of lung cancer.

\begin{tabular}{|c|c|c|c|c|}
\hline Biofluid & miRNA Signature & Size of Groups & Diagnostic Value & Reference \\
\hline Plasma & miR-21, miR-126, miR-210, miR-486 & $\begin{array}{c}\text { Control: } 29 \\
\text { Cases: } 29 \text { (Stage I-IV) }\end{array}$ & $\begin{array}{l}\mathrm{AUC}=0.86 \\
\mathrm{SEN}=75 \% \\
\mathrm{SPE}=85 \%\end{array}$ & [49] \\
\hline Plasma & miR-21, miR-335 & $\begin{array}{c}\text { Control: } 38 \\
\text { Cases: } 36 \text { (Stage I) }\end{array}$ & $\begin{array}{l}\mathrm{AUC}=0.86 \\
\mathrm{SEN}=72 \% \\
\mathrm{SPE}=81 \%\end{array}$ & [50] \\
\hline Plasma & miR-21, miR-486 & $\begin{array}{c}\text { Control: } 46 \\
\text { Cases: } 54 \text { (Stage I-III) }\end{array}$ & $\begin{array}{l}\mathrm{AUC}=0.90 \\
\mathrm{SEN}=87 \% \\
\mathrm{SPE}=87 \%\end{array}$ & {$[51]$} \\
\hline Plasma & miR-21, miR-145, miR-155 & $\begin{array}{c}\text { Control: } 92 \\
\text { Cases: } 96 \text { (Stage I-IV) }\end{array}$ & $\begin{array}{l}\mathrm{AUC}=0.85 \\
\mathrm{SEN}=69 \% \\
\mathrm{SPE}=78 \%\end{array}$ & [52] \\
\hline Plasma & $\begin{array}{l}\text { miR-101, miR-106a, miR-126, miR-133a, miR-140-3p, } \\
\text { miR-140-5p, miR-142-3p, miR-145, miR-148a, miR-15b, } \\
\text { miR-16, miR-17, miR-197, miR-19b, miR-21, miR-221, } \\
\text { miR-28-3p, miR-30b, miR-30c, miR-320, miR-451, } \\
\text { miR-486-5p, miR-660, and miR-92a } \\
\text { (Plasma miR Signature Classifier; MSC) }\end{array}$ & $\begin{array}{c}\text { Control: } 870 \\
\text { Cases: } 69 \text { (Stage I-III) }\end{array}$ & $\begin{array}{l}\mathrm{SEN}=87 \% \\
\mathrm{SPE}=81 \%\end{array}$ & [37] \\
\hline Plasma & miR-182, miR-183, miR-210, miR-126 & $\begin{array}{c}\text { Control: } 40 \\
\text { Cases: } 112 \text { (Stage I-III) }\end{array}$ & $\begin{array}{l}\mathrm{AUC}=0.97 \\
\mathrm{SEN}=81 \% \\
\mathrm{SPE}=100 \%\end{array}$ & [53] \\
\hline Plasma & miR-145, miR-20a, miR-21, miR-223 & $\begin{array}{c}\text { Control: } 83 \\
\text { Cases: } 129 \text { (Stage I-II) }\end{array}$ & $\begin{array}{l}\mathrm{AUC}=0.90 \\
\mathrm{SEN}=82 \% \\
\mathrm{SPE}=90 \%\end{array}$ & [54] \\
\hline Plasma & miR-19b, miR-21, miR-221, miR-409, miR-425, miR-584 & $\begin{array}{c}\text { Control: } 124 \\
\text { Cases: } 141 \text { (Stage I-IV) }\end{array}$ & $\begin{array}{l}\mathrm{AUC}=0.84 \\
\mathrm{SEN}=73 \% \\
\mathrm{SPE}=80 \%\end{array}$ & [55] \\
\hline Serum & $\begin{array}{l}\text { miR-92, miR-484, miR-486, miR-328, miR-191, } \\
\text { miR-376a, miR-342, miR-331, miR-30c, miR-28, miR-98, } \\
\text { miR-17, miR-26b, miR-374, miR-30b, miR-26a, miR-142, } \\
\text { miR-103, miR-126, let-7a, let-7d, let-7b, miR-32, } \\
\text { miR-133b, miR-566, miR-432, miR-223, miR-29a, } \\
\text { miR-148a, miR-142, miR-22, miR-148b, miR-140, } \\
\text { miR-139 }\end{array}$ & $\begin{array}{c}\text { Control: } 69 \\
\text { Cases: } 95 \text { (Stage I-IV) }\end{array}$ & $\begin{array}{l}\mathrm{AUC}=0.89 \\
\mathrm{SEN}=71 \% \\
\mathrm{SPE}=90 \%\end{array}$ & [38] \\
\hline Serum & miR-15b, miR-27b & $\begin{array}{c}\text { Control: } 95 \\
\text { Cases: } 85 \text { (Stage I-IV) }\end{array}$ & $\begin{array}{c}\mathrm{AUC}=0.98 \\
\mathrm{SEN}=100 \% \\
\mathrm{SPE}=84 \%\end{array}$ & [56] \\
\hline
\end{tabular}


Table 1. Cont.

\begin{tabular}{|c|c|c|c|c|}
\hline Biofluid & miRNA Signature & Size of Groups & Diagnostic Value & Reference \\
\hline Serum & $\begin{array}{c}\text { miR-92a-3p, miR-30b-5p, miR-191-5p, miR-484, } \\
\text { miR-328-3p, miR-30c-5p, miR-374a-5p, let-7d-5p, } \\
\text { miR-331-3p, miR-29a-3p, miR-148a-3p, miR-223-3p, } \\
\text { miR-140-5p } \\
\text { (miR-Test) }\end{array}$ & $\begin{array}{c}\text { Control: } 984 \\
\text { Cases: } 48 \text { (Stage I-III) }\end{array}$ & $\begin{array}{l}\mathrm{AUC}=0.85 \\
\mathrm{SEN}=72 \% \\
\mathrm{SPE}=77 \%\end{array}$ & [48] \\
\hline Serum & miR-193b, miR-301, miR-141, miR-200b & $\begin{array}{c}\text { Control: } 45 \\
\text { Cases: } 154 \text { (Stage I-III) }\end{array}$ & $\begin{array}{l}\mathrm{AUC}=0.99 \\
\mathrm{SEN}=97 \% \\
\mathrm{SPE}=96 \%\end{array}$ & [57] \\
\hline Serum & miR-483, miR-193a, miR-25, miR-214, miR-7 & $\begin{array}{c}\text { Control: } 63 \\
\text { Cases: } 63 \text { (Stage I-IV) }\end{array}$ & $\begin{array}{l}\mathrm{AUC}=0.82 \\
\mathrm{SEN}=89 \% \\
\mathrm{SPE}=68 \%\end{array}$ & {$[58]$} \\
\hline Serum & miR-152, miR-148a, miR-148b, miR-21 & $\begin{array}{c}\text { Control: } 70 \\
\text { Cases: } 70 \text { (Stage I-IV) }\end{array}$ & $\begin{array}{l}\mathrm{AUC}=0.97 \\
\mathrm{SEN}=96 \% \\
\mathrm{SPE}=91 \%\end{array}$ & [59] \\
\hline Serum & miR-15b, miR-16, miR-20a & $\begin{array}{c}\text { Control: } 58 \\
\text { Cases: } 94 \text { (Stage I-III) }\end{array}$ & $\begin{array}{l}\mathrm{AUC}=0.93 \\
\mathrm{SEN}=86 \% \\
\mathrm{SPE}=91 \%\end{array}$ & {$[60]$} \\
\hline Serum & $\begin{array}{l}\operatorname{miR}-429, \text { miR-205, } \\
\text { miR-200b, miR-203, miR-12, }\end{array}$ & $\begin{array}{c}\text { Control: } 74 \\
\text { Cases: } 138 \text { (Stage I-IV) }\end{array}$ & $\begin{array}{l}\mathrm{AUC}=0.89 \\
\mathrm{SEN}=88 \% \\
\mathrm{SPE}=71 \%\end{array}$ & {$[61]$} \\
\hline Serum & miR-141, miR-193b, miR200b, miR-301 & $\begin{array}{c}\text { Control: } 185 \\
\text { Cases: } 213 \text { (Stage I-IV) }\end{array}$ & $\begin{array}{l}\mathrm{AUC}=0.92 \\
\mathrm{SEN}=91 \% \\
\mathrm{SPE}=78 \%\end{array}$ & {$[62]$} \\
\hline Serum & miR-1268b, miR-6075 & $\begin{array}{c}\text { Control: } 2178 \\
\text { Cases: } 1566 \\
\text { (Stage I-IV) }\end{array}$ & $\begin{array}{l}\mathrm{AUC}=0.99 \\
\mathrm{SEN}=99 \% \\
\mathrm{SPE}=99 \%\end{array}$ & {$[63]$} \\
\hline
\end{tabular}

AUC-Area Under the Receiver Operating Characteristic (ROC) Curve; SEN-Sensitivity; SPE-Specificity.

\section{Exosomes, an Emerging Type of Liquid Biopsy}

Exosomes are membrane-enclosed nanovesicles $(30-150 \mathrm{~nm})$ of endosomal origin. Exosomes arise as a result of the concavity of the plasma membrane inward, resulting in the formation of an early endosome. The early endosome matures into the late endosome, which then transforms into a multivesicular body (MVB) that could attach to the plasma membrane from inside and release exosomes into the extracellular space [64,65] (Figure 1). Exosomes can be detected in various biological fluids such as urine, cerebrospinal fluid, saliva, blood, and its derivatives (serum and plasma). Exosomes are secreted by all types of cells, either non-tumorigenic and cancerous. These vesicles are enclosed by a double film of symmetrically distributed lipids containing several tetraspanins and other membrane proteins involved in the formation of MVB (CD9, CD63, CD81, TSG101, and Alix). However, the full set of proteins present in the exosome cargo (involving thousands of different cellular proteins) is variable and reflects the current phenotype of the parent cell. Except for proteins and lipids, exosomes also contain different classes of nucleic acids (single-stranded RNA, long non-coding RNA, and microRNA) and metabolites, whose composition is also regulated by the state of the cell $[64,66,67]$. 


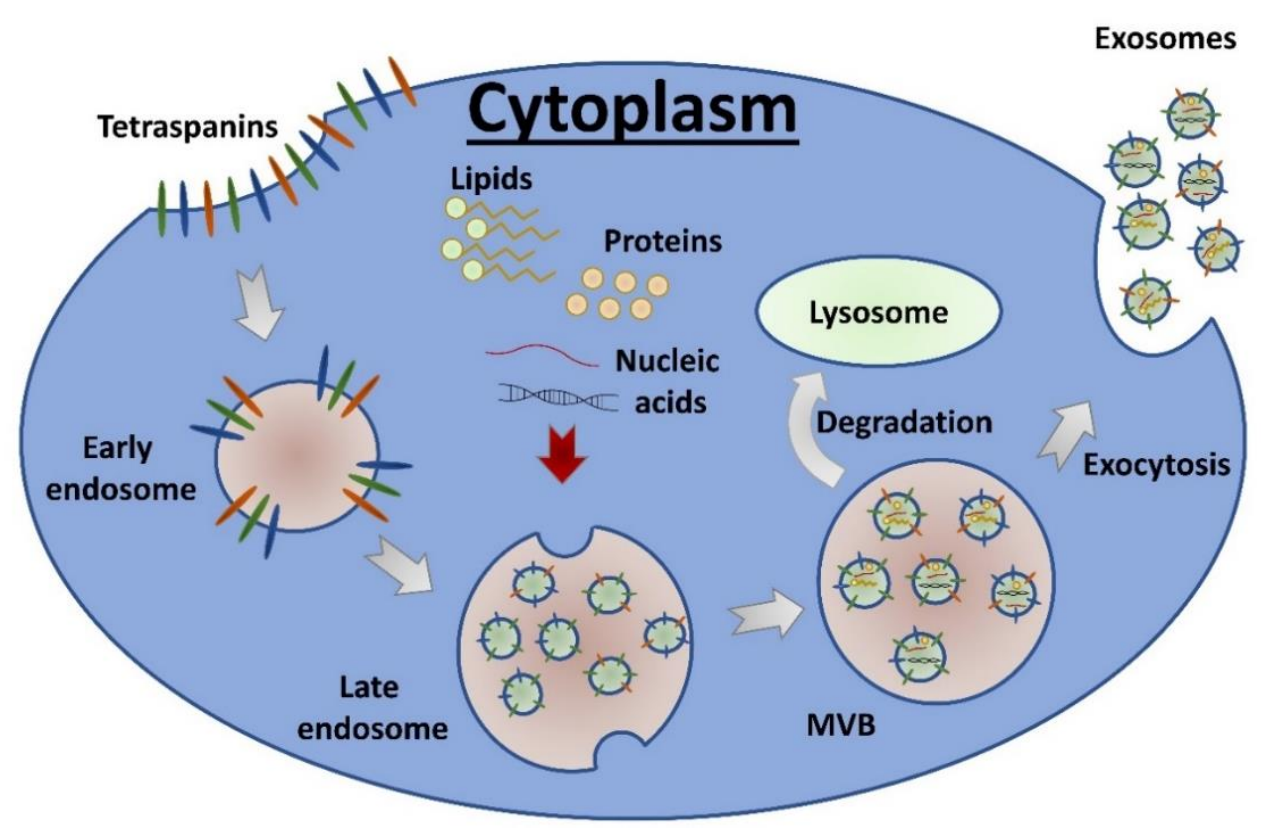

Figure 1. Biogenesis of exosomes.

In general, exosomes are involved in many aspects of cell-to-cell communication working in both paracrine and endocrine modes. In the case of exosomes from "normal" (non-tumorogenic) cells, their role in immunity, coagulation, angiogenesis, spermatogenesis, and various physiological processes in the central nervous system has been confirmed. In the case of tumor-derived exosomes (TEX), several lines of evidence indicate their association with immunomodulation, pre-metastatic niche formation, tumor growth, resistance to the treatment, and drug removal from cells [68]. TEX are signal mediators and promote disease development by participating in processes such as angiogenesis, metastasis, and many others [66,68-70]. TEX are released into the bloodstream so they can reach distant organs and modify the phenotype of many different cell types. This ability of TEX depends on their bioactive cargo, which differs from the content of exosomes released by "normal" cells and corresponds to the malignant phenotype of cancer cells [71]. Several review papers focused on the functional role of TEX have already been published, including a few recent ones $[68,70,72,73]$

Exosomes released by lung cancer cells were reported to be involved in tumor promotion, immunomodulation, and remodeling of the tumor microenvironment, also in the context of metastatic niche [66,69]. TEX secreted by lung cancer cells contain several proteins involved in tumor development, including CD91, Galectin-9, LRG1, EGFR, and Wnt5b [53,70,73-76]. Several studies also addressed the functional importance of noncoding RNA present in TEX released by lung cancer cells. For example, miR-103a present in TEX directly affected the polarization of macrophages by reducing PTEN protein expression, which in turn led to the accumulation of tumor-promoting factors such as IL10, CCL2, and VEGF-A [70,77]. Moreover, miR-21 present in TEX promoted tumor growth by increasing the permeability of blood vessels and the accumulation of hypoxia-induced factor- $1 \alpha$ (HIF-1 $\alpha$ ) under both normoxic and hypoxic conditions [78]. Other miRNAs present in TEX secreted by lung cancer cells (e.g., miR-9, miR-126, miR-122, and miR-210) could also participate in the process of angiogenesis of neoplastic blood vessels [73,74,79-82]. Long non-coding RNAs (lncRNAs) are another group of nucleic acids present in TEX secreted from lung cancer cells. It has been reported that several such lncRNAs (MALAT1, AK126698, SCAL1, and HOTAIR) are associated with the anti-apoptotic activity, resistance to cisplatin, protection of cells against oxidative stress, and increased migration proliferation and invasiveness $[74,79,83,84]$. 
The molecular composition of TEX reflects that of parental cancer cells. Therefore, TEX present in blood and other biofluids are an emerging type of liquid biopsy, considered a gold mine of potential cancer markers [26,72,85-87]. It should be emphasized, however, that exosomes represent only a subset of the heterogeneous group of extracellular vesicles (EV) that also include microvesicles (also known as ectosomes; 250-1000 nm) and apoptotic bodies (>1000 nm) formed by outward budding ("blebbing") of the plasma membrane. The term "exosomes" should be reserved for vesicles of endosomal origin that form via MVB. However, due to the limitations of current methods used for the isolation of EV the adequate discrimination between various EV subsets is not feasible. Therefore, to avoid possible misconceptions, a simplified nomenclature has been recently proposed that distinguishes small EV (i.e., $<200 \mathrm{~nm}$ ) and medium/large EV ( $>200 \mathrm{~nm}$ ). A class of small EV (sEV) consists mostly of exosomes, yet other types of EV, e.g., small microvesicles, could also copurify with this fraction [88]; in this review, the terms "exosome" and "sEV" are used interchangeably for simplicity. Moreover, sEV present in blood and other biofluids represent a complex mixture of vesicles released by different types of cells. It is estimated that TEX represent about $20-60 \%$ of sEV present in the plasma of cancer patients while the remaining exosomes and other sEV present in this specimen are released by "normal" noncancerous types of cells (e.g., platelets, immune cells, and endothelial cells) [89]. However, due to current limitations of methods allowing purification of specific TEX from body fluids [90], the mixture of different sEV that could be isolated from serum or plasma remains a feasible material in the search of cancer markers. Nevertheless, even such heterogeneous material is a promising source of biomarkers for the detection of lung cancer, which is discussed below.

\section{Serum Exosomes as Potential Lung Cancer Biomarkers}

Exosomes are secreted by various cells. However, the concentration of exosomes is much higher in the blood of cancer patients, including lung cancer, compared to healthy individuals. Recent reports indicate that the concentration of vesicles in the blood of cancer patients may reach $10^{9}$ vesicles / $\mathrm{mL}$ of blood [71]. The above observations have been confirmed in many types of cancers, including prostate cancer, ovarian cancer, breast cancer, pancreatic ductal adenocarcinoma, hepatocellular carcinoma, and breast cancer [91-95]. Increased levels of vesicles in the blood of cancer patients correlate with a worse prognosis. The molecular cargo of exosomes is the primary source of cancer biomarkers. However, apart from a different molecular cargo, TEX may have a different morphology than exosomes secreted by "normal" cells. Exosomes isolated from the serum of patients diagnosed with pancreatic cancer had a significantly smaller size compared to exosomes isolated from healthy people [91]. Similar observations were made with the use of atomic force microscopy in the case of exosomes present in patients with oral cancer [96]. Hence, the number, composition, and morphology of exosomes can be an important diagnostic cancer biomarker, though no specific data regarding lung cancer patients is available yet.

Different molecular components of exosomes existing in body fluids (serum, plasma, and saliva) of patients with lung cancer have been tested in the search for a biomarker of this malignancy [85,97-102]. Identified biomarker candidates include different classes of molecules-nucleic acids, proteins, and metabolites. Results of these studies (except for exosome miRNA discussed in the subsequent paragraph) are listed in Table 2. A few signatures of lung cancer have been proposed based on proteins present in serum/plasma-derived exosomes [86,103-107]. Moreover, several studies have proposed long non-coding RNAs and circular RNAs present in serum-derived exosomes as lung cancer biomarkers [84,108-111]. Furthermore, different levels of several phospholipids (phosphatidylcholines and sphingomyelins), triglycerides, and cholesterol esters present in the exosome membrane have been observed in plasma-derived exosomes in lung cancer patients and healthy controls [112]. Different diagnostic performance of proposed signatures was reported (Area Under the ROC Curve, AUC, was in the range 0.70 to 0.90), yet the observed difference could be attributed to differences in the statistical methodology. Nevertheless, though 
some of these biomarker candidates are promising, their actual diagnostic performance has not yet been validated in the proper clinical settings.

Table 2. Potential exosome biomarkers of lung cancer.

\begin{tabular}{|c|c|c|c|c|c|}
\hline $\begin{array}{l}\text { Biofluid/EV } \\
\text { Isolation }\end{array}$ & Size of Groups & Proposed Biomarker & Analytic. Method & Diagnostic Value & Reference \\
\hline $\begin{array}{c}\text { Serum/UC } \\
\text { TEM, NTA, WB }\end{array}$ & $\begin{array}{l}\text { Control: } 46 \\
\text { Cases: } 125 \\
\text { (Stage I-IV) }\end{array}$ & AHSG, ECM1 proteins & MS & $\begin{array}{l}\mathrm{AUC}=0.80 \\
\mathrm{SEN}=54 \% \\
\mathrm{SPE}=89 \%\end{array}$ & [104] \\
\hline Serum/IMA & $\begin{array}{l}\text { Control: } 10 \\
\text { Cases: } 26 \\
\text { (Stage III-IV) }\end{array}$ & CD91 & MS & $\begin{array}{l}\mathrm{AUC}=0.72 \\
\mathrm{SEN}=60 \% \\
\mathrm{SPE}=89 \%\end{array}$ & [105] \\
\hline $\begin{array}{c}\text { Plasma/UC } \\
\text { TEM, NTA, WB }\end{array}$ & $\begin{array}{l}\text { Control: } 15 \\
\text { Cases: } 13 \\
\text { (Stage I-II) }\end{array}$ & $\begin{array}{l}\text { SRGN, TPM3, THBS1, } \\
\text { HUWE1 proteins }\end{array}$ & MS & $\begin{array}{l}\mathrm{AUC}=0.90 \\
\mathrm{SEN}=81 \% \\
\mathrm{SPE}=82 \%\end{array}$ & [106] \\
\hline $\begin{array}{c}\text { Serum/UC } \\
\text { TEM, NTA, WB }\end{array}$ & $\begin{array}{l}\text { Control: } 90 \\
\text { Cases: } 183 \\
\text { (Stage I-IV) }\end{array}$ & $\begin{array}{l}\text { LPS-binding } \\
\text { protein (LBP) }\end{array}$ & ELISA & $\begin{array}{l}\mathrm{AUC}=0.71 \\
\mathrm{SEN}=65 \% \\
\mathrm{SPE}=76 \%\end{array}$ & [107] \\
\hline Plasma/EV array & $\begin{array}{l}\text { Control: } 150 \\
\text { Cases: } 431 \\
\text { (Stage I-IV) }\end{array}$ & $\begin{array}{l}\text { CD151, Tspan8, NYESO1, } \\
\text { HER2, CD171, EGFRvIII } \\
\text { SFTPD, Flotilin1, CD142, } \\
\text { Mucin16 }\end{array}$ & EV array & $\begin{array}{l}\mathrm{AUC}=0.74 \\
\mathrm{SEN}=71 \% \\
\mathrm{SPE}=69 \%\end{array}$ & [103] \\
\hline $\begin{array}{l}\text { Serum/PRE } \\
\text { TEA, NTA }\end{array}$ & $\begin{array}{l}\text { Control: } 150 \\
\text { Cases: } 150 \\
\text { (Stage I-IV) }\end{array}$ & lncRNA (TBILA) & qPCR & $\begin{array}{l}\mathrm{AUC}=0.78 \\
\mathrm{SEN}=65 \% \\
\mathrm{SPE}=81 \%\end{array}$ & [108] \\
\hline $\begin{array}{l}\text { Serum/PRE } \\
\text { TEA, NTA }\end{array}$ & $\begin{array}{l}\text { Control: } 150 \\
\text { Cases: } 150 \\
\text { (Stage I-IV) }\end{array}$ & lncRNA (AGAP2-AS1) & qPCR & $\begin{array}{l}\mathrm{AUC}=0.73 \\
\mathrm{SEN}=67 \% \\
\mathrm{SPE}=73 \%\end{array}$ & [108] \\
\hline $\begin{array}{c}\text { Serum/PRE } \\
\text { TEM, NTA, WB }\end{array}$ & $\begin{array}{l}\text { Control: } 64 \\
\text { Cases: } 72 \\
\text { (Stage I-IV) }\end{array}$ & lncRNA (DLX6-AS1) & qPCR & $\begin{array}{l}\mathrm{AUC}=0.81 \\
\mathrm{SEN}=78 \% \\
\mathrm{SPE}=86 \%\end{array}$ & [109] \\
\hline $\begin{array}{c}\text { Serum/PRE } \\
\text { TEM, NTA, WB }\end{array}$ & $\begin{array}{l}\text { Control: } 30 \\
\text { Cases: } 77 \\
\text { (Stage I-IV) }\end{array}$ & lncRNA (MALAT-1) & qPCR & $\begin{array}{l}\mathrm{AUC}=0.70 \\
\mathrm{SEN}=60 \% \\
\mathrm{SPE}=81 \%\end{array}$ & [85] \\
\hline $\begin{array}{c}\text { Serum/PRE } \\
\text { TEM, NTA, WB }\end{array}$ & $\begin{array}{l}\text { Control: } 40 \\
\text { Cases: } 64 \\
\text { (Stage I-IV) }\end{array}$ & lncRNA (GAS5) & qPCR & $\begin{array}{l}\mathrm{AUC}=0.86 \\
\mathrm{SEN}=86 \% \\
\mathrm{SPE}=70 \%\end{array}$ & [110] \\
\hline $\begin{array}{c}\text { Serum/PRE } \\
\text { WB }\end{array}$ & $\begin{array}{l}\text { Control: } 30 \\
\text { Cases: } 120 \\
\text { (Stage I-IV) }\end{array}$ & $\begin{array}{c}\text { circular RNA } \\
\text { (circRNA-002178) }\end{array}$ & qPCR & $\begin{array}{l}\mathrm{AUC}=0.99 \\
\mathrm{SEN}=99 \% \\
\mathrm{SPE}=100 \%\end{array}$ & [111] \\
\hline Plasma/UC & $\begin{array}{c}\text { Control: } 39 \\
\text { Cases: } 44 \\
\text { (Stage I-II) }\end{array}$ & $\begin{array}{c}\text { PC(32:0), PC(34:2), } \\
\text { PC(36:1)/(36:2)/(36:3), } \\
\text { PC(38:3)/(38:5)/(38:6), } \\
\text { LPC(12:0), LPC (16:0), } \\
\text { SM(34:1), SM(42:2), } \\
\text { TG(52:5), TG(54:6), } \\
\text { CE(20:4) }\end{array}$ & MS & $\begin{array}{l}\mathrm{AUC}=0.85 \\
\mathrm{SEN}=77 \% \\
\mathrm{SPE}=72 \%\end{array}$ & [112] \\
\hline
\end{tabular}

sEV's isolation and characterization methods: UC-Ultracentrifugation; PRE-Precipitation; IMA-Immunoaffinity; TEM-Transmission Electron Microscopy; NTA-Nanoparticle Tracking Analysis; WB-Western Blot; MS-mass spectrometry; qPCR-quantitative real-time PCR; AUC-Area Under the ROC Curve; SEN-Sensitivity; SPE-Specificity.

\section{Exosome miRNA as a Biomarker of Lung Cancer}

The miRNA content of serum/plasma-derived exosomes is another promising source of lung cancer biomarkers addressed in several papers. Two analytical methods of miRNA detection dominate in these studies-quantitative PCR and next-generation sequencing. 
However, many different approaches were applied to isolate and characterize sEV from serum or plasma; hence, different classes of vesicles could be studied in different reports. The representative papers are summarized in Table 3. Some of these studies tested the diagnostic performance of miRNA signatures, which resulted in AUC values that ranged between 0.71 and 0.98 . However, none of these signatures have yet been validated in an independent study. Furthermore, none of them have been studied in the context of lung cancer screening. Analyzed groups had different sizes and represented different clinical characteristics and ethnic/genetic backgrounds. Therefore, different miRNA signatures of serum/plasma exosomes proposed to discriminate lung cancer patients from healthy controls should be compared with caution.

Table 3. Potential sEV miRNA biomarkers of lung cancer.

\begin{tabular}{|c|c|c|c|c|}
\hline Biofluid/EV Isolation & miRNA Signature & Size of Groups & Diagnostic Value & Reference \\
\hline Plasma/PRE & $\begin{array}{l}\text { miR-378a, miR-379, miR-139-5p, } \\
\text { miR-200b-5p }\end{array}$ & $\begin{array}{c}\text { Control: } 25 \\
\text { Cases: } 80 \text { (Stage I) }\end{array}$ & $\begin{array}{l}\mathrm{AUC}=0.91 \\
\mathrm{SEN}=98 \% \\
\mathrm{SPE}=72 \%\end{array}$ & [113] \\
\hline $\begin{array}{l}\text { Plasma/PRE } \\
\text { WB, TEM }\end{array}$ & $\begin{array}{l}\text { miR-30b, miR-30c, miR-103, miR-122, } \\
\text { miR-195, miR-203, miR-221, miR-222 }\end{array}$ & $\begin{array}{c}\text { Control: } 6 \\
\text { Cases: } 12 \text { (Stage -) }\end{array}$ & - & [114] \\
\hline Plasma/PRE & miR-19-3p, miR-21-5p, miR-221-3p & $\begin{array}{c}\text { Control: } 14 \\
\text { Cases: } 18 \text { (Stage I-IV) }\end{array}$ & - & {$[55]$} \\
\hline $\begin{array}{c}\text { Plasma/PRE } \\
\text { WB, NTA, TEM }\end{array}$ & miR-23b-3p, miR-10b-5p, miR-21-5p & $\begin{array}{c}\text { Control: } 10 \\
\text { Cases: } 10 \text { (Stage I-IV) }\end{array}$ & $\begin{array}{l}\mathrm{AUC}=0.91 \\
\mathrm{SEN}=82 \% \\
\mathrm{SPE}=85 \%\end{array}$ & [115] \\
\hline $\begin{array}{l}\text { Plasma /PRE } \\
\text { WB, NTA, TEM }\end{array}$ & miR-451a, miR-194-5p, miR-486-5p & $\begin{array}{l}\text { Control: } 149 \\
\text { Cases: } 434 \\
\text { (Stage I-IV) }\end{array}$ & $\begin{array}{l}\mathrm{AUC}=0.97 \\
\mathrm{SEN}=95 \% \\
\mathrm{SPE}=71 \%\end{array}$ & [36] \\
\hline $\begin{array}{l}\text { Plasma /PRE } \\
\text { WB, NTA, TEM }\end{array}$ & $\begin{array}{l}\text { miR-185-5p, miR-32-5p, miR-140-3p, } \\
\text { let-7f-5p }\end{array}$ & $\begin{array}{l}\text { Control: } 20 \\
\text { Cases:79 } \\
\text { (Stage I-III) }\end{array}$ & $\begin{array}{l}\mathrm{AUC}=0.91 \\
\mathrm{SEN}=59 \% \\
\mathrm{SPE}=100 \%\end{array}$ & [116] \\
\hline Plasma/SEC + IMA & $\begin{array}{l}\text { miR-17-3p, miR-21, miR-106a, miR-146, } \\
\text { miR-155, miR-191, miR-192, miR-203, } \\
\text { miR-205, miR-210, miR-212, miR-214 }\end{array}$ & $\begin{array}{l}\text { Control: } 8 \\
\text { Cases: } 28 \\
\text { (Stage I-IV) }\end{array}$ & - & [117] \\
\hline Plasma/IMA & $\begin{array}{l}\text { let-7f, miR-20b, miR-30e-3p, miR-223, } \\
\text { miR-301 }\end{array}$ & $\begin{array}{l}\text { Control: } 48 \\
\text { Cases:78 } \\
\text { (Stage I-IV) }\end{array}$ & - & [118] \\
\hline $\begin{array}{c}\text { Plasma/UC + IMA } \\
\text { WB, NTA }\end{array}$ & let-7b-5p, let-7e-5p, miR-24-5p, miR-21-5p & $\begin{array}{c}\text { Control: } 13 \\
\text { Cases: } 47 \text { (Stage I) }\end{array}$ & $\begin{array}{l}\mathrm{AUC}=0.90 \\
\mathrm{SEN}=80 \% \\
\mathrm{SPE}=92 \%\end{array}$ & [119] \\
\hline $\begin{array}{l}\text { Plasma/UC } \\
\text { TEM }\end{array}$ & $\operatorname{miR}-21$, miR-4257 & $\begin{array}{l}\text { Control: } 30 \\
\text { Cases: } 195 \\
\text { (Stage I-III) }\end{array}$ & - & [120] \\
\hline Plasma/SEC & miR-411-5p & $\begin{array}{c}\text { Control: } 7 \\
\text { Cases: } 19 \text { (Stage -) }\end{array}$ & - & [121] \\
\hline Serum/PRE & $\begin{array}{l}\text { miR-451a, miR-486-5p, miR-363-3p, } \\
\text { miR-660-5p, miR-15b-5p, miR-25-3p, } \\
\text { miR-16-2-3p }\end{array}$ & $\begin{array}{l}\text { Control: } 10 \\
\text { Cases: } 20 \\
\text { (Stage I-IV) }\end{array}$ & $\begin{array}{l}\mathrm{AUC}=0.98 \\
\mathrm{SEN}=100 \% \\
\mathrm{SPE}=90 \%\end{array}$ & [122] \\
\hline $\begin{array}{c}\text { Serum/PRE } \\
\text { WB, NTA, TEM }\end{array}$ & miR-17-5p & $\begin{array}{l}\text { Control: } 137 \\
\text { Cases: } 172 \\
\text { (Stage I-III) }\end{array}$ & $\begin{array}{l}\mathrm{AUC}=0.74 \\
\mathrm{SEN}=67 \% \\
\mathrm{SPE}=77 \%\end{array}$ & [123] \\
\hline $\begin{array}{c}\text { Serum/PRE } \\
\text { WB, NTA, TEM }\end{array}$ & $\operatorname{miR}-146 a-5 p, \operatorname{miR}-486-5 p$ & $\begin{array}{c}\text { Control: } 80 \\
\text { Cases: } 48 \\
\text { (Stage I-II) }\end{array}$ & $\begin{array}{l}\mathrm{AUC}=0.90 \\
\mathrm{SEN}=83 \% \\
\mathrm{SPE}=90 \%\end{array}$ & [124] \\
\hline
\end{tabular}


Table 3. Cont

\begin{tabular}{|c|c|c|c|c|}
\hline Biofluid/EV Isolation & miRNA Signature & Size of Groups & Diagnostic Value & Reference \\
\hline Serum/PRE & miR-216b & $\begin{array}{l}\text { Control: } 60 \\
\text { Cases: } 105 \\
\text { (Stage I-IV) }\end{array}$ & $\begin{array}{l}\mathrm{AUC}=0.84 \\
\mathrm{SEN}=87 \% \\
\mathrm{SPE}=75 \%\end{array}$ & [125] \\
\hline $\begin{array}{l}\text { Serum/PRE } \\
\text { WB, TEM }\end{array}$ & miR-106b & $\begin{array}{c}\text { Control: } 72 \\
\text { Cases: } 72 \\
\text { (Stage I-IV) }\end{array}$ & - & [126] \\
\hline Serum/PRE & 106a-5p, miR-20a-5p, miR-93-5p & $\begin{array}{c}\text { Control: } 36 \\
\text { Cases: } 34 \\
\text { (Stage I-III) }\end{array}$ & $\mathrm{AUC}=0.83$ & [127] \\
\hline $\begin{array}{c}\text { Serum/PRE } \\
\text { WB, NTA, TEM }\end{array}$ & $\begin{array}{l}\text { miR-210-5p, miR-1269a, miR-205-5p, } \\
\text { miR-9-3p }\end{array}$ & $\begin{array}{l}\text { Control: } 150 \\
\text { Cases: } 148 \\
\text { (Stage I-III) }\end{array}$ & $\begin{array}{l}\mathrm{AUC}=0.74 \\
\mathrm{SEN}=81 \% \\
\mathrm{SPE}=61 \%\end{array}$ & [128] \\
\hline $\begin{array}{c}\text { Serum/PRE } \\
\text { WB, NTA, TEM }\end{array}$ & $\operatorname{miR}-1290$ & $\begin{array}{c}\text { Control: } 40 \\
\text { Cases: } 70 \\
\text { (Stage I-IV) }\end{array}$ & $\begin{array}{l}\mathrm{AUC}=0.94 \\
\mathrm{SEN}=80 \% \\
\mathrm{SPE}=97 \%\end{array}$ & [129] \\
\hline Serum/PRE & $\operatorname{miR}-378$ & $\begin{array}{l}\text { Control: } 60 \\
\text { Cases: } 103 \\
\text { (Stage I-IV) }\end{array}$ & $\begin{array}{l}\mathrm{AUC}=0.84 \\
\mathrm{SEN}=78 \% \\
\mathrm{SPE}=82 \%\end{array}$ & [130] \\
\hline $\begin{array}{l}\text { Serum/PRE } \\
\text { WB, TEM }\end{array}$ & miR-7977, miR-98-3p & $\begin{array}{c}\text { Control: } 65 \\
\text { Cases: } 65 \\
\text { (Stage I-IV) }\end{array}$ & $\begin{array}{l}\mathrm{AUC}=0.82 \\
\mathrm{SEN}=81 \% \\
\mathrm{SPE}=75 \%\end{array}$ & [131] \\
\hline $\begin{array}{c}\text { Serum/UC } \\
\text { WB, NTA, TEM }\end{array}$ & miR-126 & $\begin{array}{c}\text { Control: } 31 \\
\text { Cases: } 45 \\
\text { (Stage I-III) }\end{array}$ & $\begin{array}{l}\mathrm{AUC}=0.84 \\
\mathrm{SEN}=90 \% \\
\mathrm{SPE}=86 \%\end{array}$ & [132] \\
\hline $\begin{array}{c}\text { Serum/UC } \\
\text { WB, NTA, TEM }\end{array}$ & miR-21-5p, miR-126-3p, miR-140-5p & $\begin{array}{l}\text { Control: } 16 \\
\text { Cases: } 23 \\
\text { (Stage I-IV) }\end{array}$ & - & [133] \\
\hline $\begin{array}{c}\text { Serum/UC } \\
\text { WB, NTA, TEM }\end{array}$ & miR-620 & $\begin{array}{c}\text { Control: } 231 \\
\text { Cases: } 235 \\
\text { (Stage I-IV) }\end{array}$ & $\begin{array}{l}\mathrm{AUC}=0.71 \\
\mathrm{SEN}=63 \% \\
\mathrm{SPE}=68 \%\end{array}$ & [134] \\
\hline $\begin{array}{c}\text { Serum/UC } \\
\text { WB, NTA, TEM }\end{array}$ & miR-5684, miR-125b-5p & $\begin{array}{c}\text { Control: } 312 \\
\text { Cases: } 330 \\
\text { (Stage I-IV) }\end{array}$ & $\begin{array}{l}\mathrm{AUC}=0.74 \\
\mathrm{SEN}=81 \% \\
\mathrm{SPE}=61 \%\end{array}$ & [135] \\
\hline $\begin{array}{c}\text { Serum/UC } \\
\text { WB, NTA, TEM }\end{array}$ & miR-20b-5p, miR-3187-5p & $\begin{array}{l}\text { Control: } 30 \\
\text { Cases: } 380 \\
\text { (Stage } 0-\mathrm{I})\end{array}$ & $\mathrm{AUC}=0.84$ & [136] \\
\hline
\end{tabular}

sEV's isolation and characterization methods: UC—Ultracentrifugation; PRE-Precipitation; IMA—Immunoaffinity; SEC-Size Exclusion Chromatography; TEM-Transmission Electron Microscopy; NTA-Nanoparticle Tracking Analysis; WB-Western Blot; AUC—Area Under the ROC Curve; SEN—Sensitivity; SPE—Specificity.

According to current literature research, proposed lung cancer exosome signatures involved above 60 miRNA species overall, and 14 miRNA species appeared in more than one signature. This included miR-21 (seven signatures), miR-221 (three signatures), and miR-486-5p (three signatures). Figure 2 illustrates miRNA species present in lung cancer signatures, detected in either whole serum/plasma or serum/plasma-derived exosomes, which were included in more than one signature. There were nine miRNA species, namely, miR-17, miR-19, miR-21, miR-221, miR-451, miR-486-5p, miR-126, miR-140, and miR-210, which appeared in both whole serum/plasma and exosome-based signatures. Functions associated with this interesting subset of miRNAs are discussed below. 


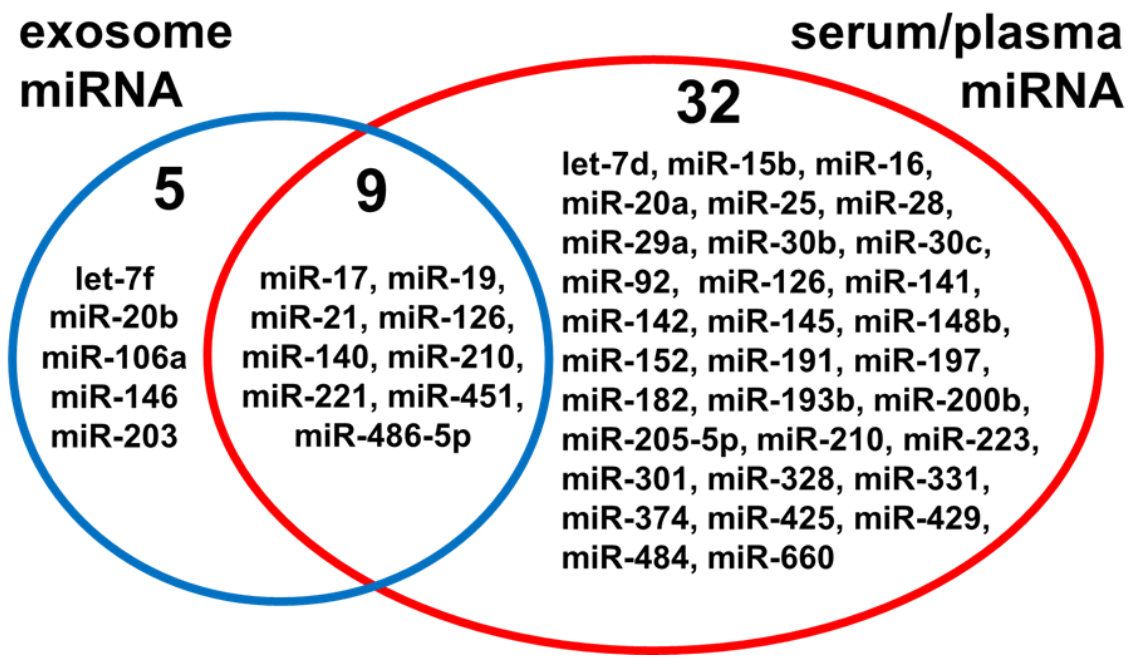

Figure 2. MicroRNA species present in lung cancer signatures. Showed are components present in at least 2 signatures identified in either whole serum/plasma or serum/plasma-derived exosomes (small extracellular vesicles).

Shared components of the whole serum/plasma-based and exosome-based lung cancer signatures contain several oncomirs, i.e., miRNAs with known cancer-related functions. These include miR-17 and miR-19 belonging to the miR-17-92 cluster, which is regulated by MYC. The miR-17-92 cluster is a unique oncomir due to the polycistronic miRNA transcript, which allows obtaining six individual miRNAs involved in many cancer-associated processes: miR-17, miR-18a, miR-19a, miR-20a, miR-19b-1, and miR-92a-1 [137]. A high level of miR-17 and miR-19 induces cell proliferation, while the deletion is lethal (it causes lung and lymphoid cell developmental defects) [138]. miR-17 suppresses the expression of the E2F1 transcription factor, shifting the cellular balance in favor of increased proliferation. In lung cancer, overexpression of miR-17 and miR-19 affects the expression of HIF1A, PTEN, $B C L 2 L 11, C D K N A$, and TSP1, enhancing tumor growth by increasing the permeability of blood vessels, inducing hypoxia, increasing proliferation, inhibiting apoptosis, and stimulating tumor cell migration $[139,140]$. miR-21 is another oncomir frequently overexpressed in cancer cells, one of the first miRNAs identified in mammals. Among the targets of miR-21 are tumor suppressor genes such as PTEN, RHOB, and TP63. Further, miR-21 blocks AKT and MAPK signaling pathways via inhibition of several phosphatases. As a result of miR-21 overexpression, the action of tumor suppressors is blocked, causing the development of many cancers such as lung, ovarian, breast, brain, and many others [141]. In lung cancer, overexpression of miR-21 is associated with increased cell proliferation, angiogenesis, cell invasion, and metastasis, as well as chemo- and radioresistance [142]. The inhibition of miR-21 resulted in the induction of apoptosis (due to inhibiting the $\mathrm{PI} 3 \mathrm{~K} / \mathrm{Akt} / \mathrm{NF}-\mathrm{KB}$ signaling pathway and increased caspase activity) as well as impeded the migration and invasiveness of NSCLC cells [143]. miR-21 is involved in modulating the tumor microenvironment by targeting PTEN in the stromal compartment, which is mediated by miR-21-containing TEX [144]. Another oncogenic miRNA found in TEX is miR-221. miR-221 inhibits p27 tumor suppressor, which causes the transition from G1 to $\mathrm{S}$ phase and acceleration of cell division [145]. Among miR-221 targets is also CD117, a known proto-oncogene that regulates cell survival, migration, and differentiation. Overexpression of miR-221 induces proliferation and migration of tumor cells as well as tumor angiogenesis via the $\mathrm{Wnt} / \beta$-catenin signaling pathway and has been shown to promote the chemoresistance of lung cancer cells by activating the PTEN/Akt pathway [146]. miR-210 is also an important factor in the development of lung cancer, whose level increases in NSCLS tissues and is associated with a worse prognosis [147]. The action of miR-210 involves the regulation of HIF-1, ATG7, LC3, and Beclin-1 [148]. 
Other miRNA observed in multiple lung cancer signatures are putative tumor suppressors. In lung cancer, a decreased level of miR-451 correlates with poor prognosis [149]. Functionally, decreased expression of miR-451 increases drug resistance and accelerates the epithelial-mesenchymal transition due to MYC overexpression, which is a miR-451 target [150]. Moreover, miR-451 targets several genes involved in the inflammation and stress response pathways that modulate the tumor microenvironment, including PSMB8, NOS2, and CARF [151]. Another component of exosome lung cancer signature is miR-126, which level was reduced in cancer patients. Overexpression of miR-126 inhibits cancer cell proliferation, colony formation, migration, invasion, induces cell cycle arrest, and apoptosis via targeting ITGA6 gene [152]. Another characteristic component of serum-derived exosomes is miR-140 involved in carcinogenesis and tumor progression, which level is significantly lowered in tumors. Overexpression of miR-140 is associated with inhibition of proliferation, migration, and invasion of NSCLC cells via targeting of ATP8A1 and IGF1R genes [153,154] Another miRNA shared by serum and exosome-based signatures is miR-486-5p. This miRNA, one of the most abundant miRNAs in the peripheral blood, plays an important role in the development of many cancers. Overexpression of miR-486-5p increases cell proliferation by regulating the PTEN/PI3K/AKT pathway [155]. On the other hand, however, decreased levels of miRNA-486-5p in NSCLC tissues correlated with increased drug resistance and a worse prognosis [156]. Moreover, overexpression of miR-486-5p inhibits the development of lung cancer due to the suppression of GAB2 [157]. Further, decreased level of miRNA-486-5p correlates with KIAA1199 protein overexpression, which in turn results in increased cancer proliferation and poor prognosis [158].

Interesting cancer-related features could be attributed also to five miRNA species detected only in exosome-based signatures of lung cancer, namely, let-7f, miR-146, miR-203, miR-106a, and miR-20b. Let-7f belongs to the let-7 (lethal-7) family, which consists of 12 members that regulate cell cycle and cell proliferation by affecting RAS, cyclin A2, CDC34, Aurora A and B kinases, E2F5, CDK8, and HMGA2 [159]. Decreased expression of let-7 is observed in different tumor tissues [160]. Increased expression of let-7f is associated with inhibition of proliferation, migration, and invasion of neoplastic cells, including lung cancer cells, while its decreased expression was observed in metastatic cells [161]. miR-146 is involved in the regulation of inflammation [162]. The overexpression of miR-146 is associated with increased survival and migration of NSCLC cells via suppressing TRAF6 [163]. Further, increased expression of miR-146 in lung cancer cells lowers the level of claudin-12, which in turn leads to activation of the Wnt/ $\beta$-catenin and PI3K/AKT/MAPK signaling pathways resulting in the increased viability and migration, as well as resistance to cisplatin and inhibition of apoptosis [164]. Another oncogenic miRNA observed in exosomes of lung cancer patients is miR-106, which increased expression correlates lymph node metastases, drug resistance, and poor prognosis [165]. Increased level of miR-106 decreased expression of $B T G 3$, which in turn promotes proliferation and inhibits apoptosis [166]. The expression of miR-20b is also significantly higher in lung cancer cells. miR-20b contributes to the development of NSCLC by inhibiting APC via the canonical Wnt signaling pathway [167]. Moreover, similar to miR-106, miR-20b directly targets BTG3 [168]. The last miRNA detected in multiple lung cancer signatures is miR-203, which is a putative tumor suppressor. High expression of miR-203 inhibits the proliferation and invasiveness of lung cancer cells through negative regulation of survivin [169]. Moreover, increased expression of miR-203 inhibits RGS17 oncogene, which results in reduced cell proliferation through the cAMP-PKA-CREB pathway [170]. Furthermore, miR-203 acts as a suppressor of the SRC/Ras/ERK pathway by inhibiting the expression of $S R C$ oncogene, resulting in the suppression of proliferation and migration of lung cancer cells [171].

Furthermore, to search systemically for genes regulated by 14 miRNA species that recurred in sEV-based signatures of lung cancer (Figure 2), the miRTarBase database of experimentally validated interactions between miRNA and genes [172] was analyzed. This returned the set of about 600 genes, which functions were analyzed using the FunRich functional enrichment analysis tool [173]. The set comprised of 390 genes associated with 
lung cancer, including several ones responsible for clinical features of this cancer (e.g., KRAS, EGFR, CASP8, PIK3CA, ERBB2, FASLG, RB1, MYD88, and TP53). Among molecular functions and biological processes associated with this set of genes, several terms potentially involved in cancer development and progression were significantly over-represented, which is summarized in Table 4. Moreover, over-represented biological pathways associated with the most numerous subsets of genes were outweighed by signaling pathways associated with inflammation, immune response, cell growth, cell-to-cell communication, and cancer.

Table 4. Functions associated with genes regulated by exosome miRNAs common in lung cancer signatures.

\begin{tabular}{|c|c|c|c|}
\hline Molecular Function & No. of Genes & Fold Enrichment & FDR \\
\hline Transcription factor activity & 72 & 2.64 & $<0.00001$ \\
\hline Receptor activity & 32 & 2.73 & 0.00003 \\
\hline Protein serine/threonine kinase activity & 28 & 2.87 & 0.00005 \\
\hline Transmembrane receptor protein tyrosine kinase activity & 11 & 6.06 & 0.00008 \\
\hline Receptor signaling complex scaffold activity & 28 & 2.68 & 0.00010 \\
\hline Receptor binding & 16 & 3.83 & 0.00016 \\
\hline Protein-tyrosine kinase activity & 8 & 6.50 & 0.00077 \\
\hline Transcription regulator activity & 47 & 1.74 & 0.00451 \\
\hline GTPase activity & 18 & 2.50 & 0.00868 \\
\hline Kinase regulator activity & 5 & 6.71 & 0.01639 \\
\hline Biological Process & No. of Genes & Fold Enrichment & FDR \\
\hline Signal transduction & 240 & 1.88 & $<0.00001$ \\
\hline Cell communication & 223 & 1.85 & $<0.00001$ \\
\hline Regulation of nucleotide and nucleic acid metabolism & 144 & 1.57 & $<0.00001$ \\
\hline Apoptosis & 26 & 3.64 & $<0.00001$ \\
\hline Regulation of cell growth & 5 & 7.35 & 0.01662 \\
\hline
\end{tabular}

No. of genes—number of genes connected to specific term among 600 genes in the whole set; FDR—corrected p-value of the hypergeometric test for the significance of over-representation.

\section{Conclusions}

MicroRNA component of serum/plasma is an attractive source of cancer biomarkers, and several miRNA signatures of lung cancer have been proposed. Though none of them is applied in clinical practice yet, a few are currently tested in prospective clinical trials aimed at validation of their applicability in the early detection of lung cancer and/or diagnosis of the indeterminate pulmonary nodules. Among other potential biomarkers of early lung cancer are exosomes (or rather small extracellular vesicle, sEV) circulating in the blood. Several molecular components of sEV, including proteins, lipids, and noncoding RNAs, have been reported to have different levels in vesicles isolated from lung cancer patients and healthy individuals. The largest number of published reports that address this issue focus on the miRNA component of vesicles. Proposed signatures of exosome miRNA have promising diagnostic value (AUC in the $0.75-0.95$ range), yet none of them has been validated in the context of the early detection of lung cancer. These signatures involve a few dozen miRNA species overall, including 14 miRNA (so far) that recurred in different signatures. It is worth noting that all these miRNA species have cancerrelated functions and have been associated with lung cancer progression, which further confirms their diagnostic importance. Importantly, a few miRNA species, including known oncomirs miR-17, miR-19, and miR-21, appear in multiple miRNA signatures of lung cancer that are based on both the whole serum/plasma and serum/plasma-derived exosomes. However, one should note, that due to barely standardized methods of sEV isolation, the analysis of exosome miRNA content represents a diagnostic challenge. Therefore, the direct comparison of a diagnostic value of miRNA signature based on the serum/plasma-derived $\mathrm{sEV}$ and the whole specimen is desired, which is not available yet. 
Author Contributions: Writing—original draft preparation, M.S.; writing—review and editing, P.W. All authors have read and agreed to the published version of the manuscript.

Funding: This work was supported by the National Science Centre, Poland, Grant 2017/27/B/NZ7/01833 (to P.W.).

Institutional Review Board Statement: Not applicable.

Informed Consent Statement: Not applicable.

Data Availability Statement: Not applicable.

Conflicts of Interest: The authors declare no conflict of interest.

\section{References}

1. Blandin Knight, S.; Crosbie, P.A.; Balata, H.; Chudziak, J.; Hussell, T.; Dive, C. Progress and prospects of early detection in lung cancer. Open Biol. 2017, 7, 170070. [CrossRef]

2. Kauczor, H.U.; Baird, A.M.; Blum, T.G.; Bonomo, L.; Bostantzoglou, C.; Burghuber, O.; Čepická, B.; Comanescu, A.; Couraud, S.; Devaraj, A.; et al. ESR/ERS statement paper on lung cancer screening. Eur. Radiol. 2020, 30, 3277-3294. [CrossRef] [PubMed]

3. Aberle, D.R.; Adams, A.M.; Berg, C.D.; Black, W.C.; Clapp, J.D.; Fagerstrom, R.M.; Gareen, I.F.; Gatsonis, C.; Marcus, P.M.; Sicks, J.D. Reduced lung-cancer mortality with low-dose computed tomographic screening. N. Engl. J. Med. 2011, 365, 395-409. [CrossRef] [PubMed]

4. $\quad$ de Koning, H.J.; van der Aalst, C.M.; de Jong, P.A.; Scholten, E.T.; Nackaerts, K.; Heuvelmans, M.A.; Lammers, J.J.; Weenink, C.; Yousaf-Khan, U.; Horeweg, N.; et al. Reduced Lung-Cancer Mortality with Volume CT Screening in a Randomized Trial. N. Engl. J. Med. 2020, 382, 503-513. [CrossRef] [PubMed]

5. Wille, M.M.; Dirksen, A.; Ashraf, H.; Saghir, Z.; Bach, K.S.; Brodersen, J.; Clementsen, P.F.; Hansen, H.; Larsen, K.R.; Mortensen, J.; et al. Results of the Randomized Danish Lung Cancer Screening Trial with Focus on High-Risk Profiling. Am. J. Respir. Crit. Care Med. 2016, 193, 542-551. [CrossRef]

6. Priola, A.M.; Priola, S.M.; Giaj-Levra, M.; Basso, E.; Veltri, A.; Fava, C.; Cardinale, L. Clinical implications and added costs of incidental findings in an early detection study of lung cancer by using low-dose spiral computed tomography. Clin. Lung Cancer 2013, 14, 139-148. [CrossRef] [PubMed]

7. Rzyman, W.; Jelitto-Gorska, M.; Dziedzic, R.; Biadacz, I.; Ksiazek, J.; Chwirot, P.; Marjanski, T. Diagnostic work-up and surgery in participants of the Gdansk lung cancer screening programme, the incidence of surgery for non-malignant conditions. Interact. Cardiovasc. Thorac. Surg. 2013, 17, 969-973. [CrossRef]

8. Hasan, N.; Kumar, R.; Kavuru, M.S. Lung cancer screening beyond low-dose computed tomography: The role of novel biomarkers. Lung 2014, 192, 639-648. [CrossRef]

9. Atwater, T.; Massion, P.P. Biomarkers of risk to develop lung cancer in the new screening era. Ann. Transl. Med. 2016, 4, 158. [CrossRef]

10. Chu, G.C.W.; Lazare, K.; Sullivan, F. Serum and blood based biomarkers for lung cancer screening, a systematic review. BMC Cancer 2018, 18, 181. [CrossRef]

11. Ostrin, E.J.; Sidransky, D.; Spira, A.; Hanash, S.M. Biomarkers for Lung Cancer Screening and Detection. Cancer Epidemiol. Biomark. Prev. 2020, 29, 2411-2415. [CrossRef] [PubMed]

12. Hassanein, M.; Callison, J.C.; Callaway-Lane, C.; Aldrich, M.C.; Grogan, E.L.; Massion, P.P. The state of molecular biomarkers for the early detection of lung cancer. Cancer Prev. Res. 2012, 5, 992-1006. [CrossRef]

13. Zamay, T.N.; Zamay, G.S.; Kolovskaya, O.S.; Zukov, R.A.; Petrova, M.M.; Gargaun, A.; Berezovski, M.V.; Kichkailo, A.S. Current and Prospective Protein Biomarkers of Lung Cancer. Cancers 2017, 9, 155. [CrossRef]

14. Leighl, N.B.; Page, R.D.; Raymond, V.M.; Daniel, D.B.; Divers, S.G.; Reckamp, K.L.; Villalona-Calero, M.A.; Dix, D.; Odegaard, J.I.; Lanman, R.B.; et al. Clinical Utility of Comprehensive Cell-free DNA Analysis to Identify Genomic Biomarkers in Patients with Newly Diagnosed Metastatic Non-small Cell Lung Cancer. Clin. Cancer Res. 2019, 25, 4691-4700. [CrossRef]

15. Maly, V.; Maly, O.; Kolostova, K.; Bobek, V. Circulating Tumor Cells in Diagnosis and Treatment of Lung Cancer. In Vivo 2019, 33, 1027-1037. [CrossRef] [PubMed]

16. Lee, K.B.; Ang, L.; Yau, W.P.; Seow, W.J. Association between Metabolites and the Risk of Lung Cancer, A Systematic Literature Review and Meta-Analysis of Observational Studies. Metabolites 2020, 10, 362. [CrossRef] [PubMed]

17. Ros-Mazurczyk, M.; Jelonek, K.; Marczyk, M.; Binczyk, F.; Pietrowska, M.; Polanska, J.; Dziadziuszko, R.; Jassem, J.; Rzyman, W.; Widlak, P. Serum lipid profile discriminates patients with early lung cancer from healthy controls. Lung Cancer 2017, 112, 69-74. [CrossRef] [PubMed]

18. Seijo, L.M.; Peled, N.; Ajona, D.; Boeri, M.; Field, J.K.; Sozzi, G.; Pio, R.; Zulueta, J.J.; Spira, A.; Massion, P.P.; et al. Biomarkers in Lung Cancer Screening: Achievements, Promises, and Challenges. J. Thorac. Oncol. 2019, 14, 343-357. [CrossRef] [PubMed]

19. Duffy, M.J.; O’Byrne, K. Tissue and Blood Biomarkers in Lung Cancer, A Review. Adv. Clin. Chem. 2018, 86, 1-21. [CrossRef]

20. Vargas, A.J.; Harris, C.C. Biomarker development in the precision medicine era, lung cancer as a case study. Nat. Rev. Cancer 2016, 16, 525-537. [CrossRef] 
21. Dama, E.; Melocchi, V.; Colangelo, T.; Cuttano, R.; Bianchi, F. Deciphering the Molecular Profile of Lung Cancer: New Strategies for the Early Detection and Prognostic Stratification. J. Clin. Med. 2019, 8, 108. [CrossRef] [PubMed]

22. Mazzone, P.J.; Sears, C.R.; Arenberg, D.A.; Gaga, M.; Gould, M.K.; Massion, P.P.; Nair, V.S.; Powell, C.A.; Silvestri, G.A.; Vachani, A.; et al. ATS Assembly on Thoracic Oncology. Evaluating Molecular Biomarkers for the Early Detection of Lung Cancer, When Is a Biomarker Ready for Clinical Use? An Official American Thoracic Society Policy Statement. Am. J. Respir. Crit. Care Med. 2017, 196, e15-e29. [CrossRef] [PubMed]

23. Massion, P.P.; Healey, G.F.; Peek, L.J.; Fredericks, L.; Sewell, H.F.; Murray, A.; Robertson, J.F. Autoantibody Signature Enhances the Positive Predictive Power of Computed Tomography and Nodule-Based Risk Models for Detection of Lung Cancer. J. Thorac. Oncol. 2017, 12, 578-584. [CrossRef]

24. Silvestri, G.A.; Tanner, N.T.; Kearney, P.; Vachani, A.; Massion, P.P.; Porter, A.; Springmeyer, S.C.; Fang, K.C.; Midthun, D.; Mazzone, P.J.; et al. Assessment of Plasma Proteomics Biomarker's Ability to Distinguish Benign From Malignant Lung Nodules, Results of the PANOPTIC (Pulmonary Nodule Plasma Proteomic Classifier) Trial. Chest 2018, 154, 491-500. [CrossRef] [PubMed]

25. Han, Y.; Li, H. miRNAs as biomarkers and for the early detection of non-small cell lung cancer (NSCLC). J. Thorac. Dis. 2018, 10, 3119-3131. [CrossRef]

26. Rijavec, E.; Coco, S.; Genova, C.; Rossi, G.; Longo, L.; Grossi, F. Liquid Biopsy in Non-Small Cell Lung Cancer: Highlights and Challenges. Cancers 2019, 12, 17. [CrossRef] [PubMed]

27. Iqbal, M.A.; Arora, S.; Prakasam, G.; Calin, G.A.; Syed, M.A. MicroRNA in lung cancer: Role, mechanisms, pathways and therapeutic relevance. Mol. Aspects Med. 2019, 70, 3-20. [CrossRef] [PubMed]

28. Vishnoi, A.; Rani, S. MiRNA Biogenesis and Regulation of Diseases: An Overview. Methods Mol. Biol. 2017, 1509, 1-10. [CrossRef]

29. Liu, G.; Li, B. Role of miRNA in transformation from normal tissue to colorectal adenoma and cancer. J. Cancer Res. Ther. 2019, 15, 278-285. [CrossRef]

30. Abreu, F.B.; Liu, X.; Tsongalis, G.J. miRNA analysis in pancreatic cancer: The Dartmouth experience. Clin. Chem. Lab. Med. 2017, 55, 755-762. [CrossRef]

31. Ghafouri-Fard, S.; Shoorei, H.; Taheri, M. miRNA profile in ovarian cancer. Exp. Mol. Pathol. 2020, 113, 104381. [CrossRef] [PubMed]

32. Balacescu, O.; Dumitrescu, R.G.; Marian, C. MicroRNAs Role in Prostate Cancer. Methods Mol. Biol. 2018, 1856, 103-117. [CrossRef]

33. Wang, N.; Guo, W.; Song, X.; Liu, L.; Niu, L.; Song, X.; Xie, L. Tumor-associated exosomal miRNA biomarkers to differentiate metastatic vs. nonmetastatic non-small cell lung cancer. Clin. Chem. Lab. Med. 2020, 58, 1535-1545. [CrossRef] [PubMed]

34. Montani, F.; Bianchi, F. Circulating Cancer Biomarkers: The Macro-revolution of the Micro-RNA. EBioMedicine 2016, 5, 4-6. [CrossRef] [PubMed]

35. He, W.J.; Li, W.H.; Jiang, B.; Wang, Y.F.; Xia, Y.X.; Wang, L. MicroRNAs level as an initial screening method for early-stage lung cancer, a bivariate diagnostic random-effects meta-analysis. Int. J. Clin. Exp. Med. 2015, 8, 12317-12326.

36. Yao, B.; Qu, S.; Hu, R.; Gao, W.; Jin, S.; Liu, M.; Zhao, Q. A panel of miRNAs derived from plasma extracellular vesicles as novel diagnostic biomarkers of lung adenocarcinoma. FEBS Open Biol. 2019, 9, 2149-2158. [CrossRef]

37. Sozzi, G.; Boeri, M.; Rossi, M.; Verri, C.; Suatoni, P.; Bravi, F.; Roz, L.; Conte, D.; Grassi, M.; Sverzellati, N.; et al. Clinical utility of a plasma-based miRNA signature classifier within computed tomography lung cancer screening, a correlative MILD trial study. $J$. Clin. Oncol. 2014, 32, 768-773. [CrossRef] [PubMed]

38. Bianchi, F.; Nicassio, F.; Marzi, M.; Belloni, E.; Dall'olio, V.; Bernard, L.; Pelosi, G.; Maisonneuve, P.; Veronesi, G.; Di Fiore, P.P. A serum circulating miRNA diagnostic test to identify asymptomatic high-risk individuals with early stage lung cancer. $E M B O \mathrm{Mol}$. Med. 2011, 3, 495-503. [CrossRef]

39. Lu, T.P.; Lee, C.Y.; Tsai, M.H.; Chiu, Y.C.; Hsiao, C.K.; Lai, L.C.; Chuang, E.Y. miRSystem, an integrated system for characterizing enriched functions and pathways of microRNA targets. PLoS ONE 2012, 7, e42390. [CrossRef] [PubMed]

40. Nguyen, J.; Bernert, R.; In, K.; Kang, P.; Sebastiao, N.; Hu, C.; Hastings, K.T. Gamma-interferon-inducible lysosomal thiol reductase is upregulated in human melanoma. Melanoma Res. 2016, 26, 125-137. [CrossRef]

41. Pucer, A.; Brglez, V.; Payré, C.; Pungerčar, J.; Lambeau, G.; Petan, T. Group X secreted phospholipase A(2) induces lipid droplet formation and prolongs breast cancer cell survival. Mol. Cancer 2013, 12, 111. [CrossRef]

42. Coulier, F.; Batoz, M.; Marics, I.; de Lapeyrière, O.; Birnbaum, D. Putative structure of the FGF6 gene product and role of the signal peptide. Oncogene 1991, 6, 1437-1444.

43. Li, J.X.; Zhang, Z.F.; Wang, X.B.; Yang, E.Q.; Dong, L.; Meng, J. PLZF regulates apoptosis of leukemia cells by regulating AKT/Foxo3a pathway. Eur. Rev. Med. Pharmacol. Sci. 2019, 23, 6411-6418. [CrossRef]

44. Kim, G.Y.; Kim, H.; Lim, H.J.; Park, H.Y. Coronin 1A depletion protects endothelial cells from TNF $\alpha$-induced apoptosis by modulating p38 $\beta$ expression and activation. Cell. Signal. 2015, 27, 1688-1693. [CrossRef]

45. Wang, H.; Wu, S.; Zhao, L.; Zhao, J.; Liu, J.; Wang, Z. Clinical use of microRNAs as potential non-invasive biomarkers for detecting non-small cell lung cancer, a meta-analysis. Respirology 2015, 20, 56-65. [CrossRef] [PubMed]

46. Shen, Y.; Wang, T.; Yang, T.; Hu, Q.; Wan, C.; Chen, L.; Wen, F. Diagnostic value of circulating microRNAs for lung cancer, a meta-analysis. Genet. Test. Mol. Biomark. 2013, 17, 359-366. [CrossRef] [PubMed]

47. Jiang, M.; Li, X.; Quan, X.; Li, X.; Zhou, B. Clinically Correlated MicroRNAs in the Diagnosis of Non-Small Cell Lung Cancer, A Systematic Review and Meta-Analysis. Biomed. Res. Int. 2018, 2018, 5930951. [CrossRef] [PubMed] 
48. Montani, F.; Marzi, M.J.; Dezi, F.; Dama, E.; Carletti, R.M.; Bonizzi, G.; Bertolotti, R.; Bellomi, M.; Rampinelli, C.; Maisonneuve, P.; et al. miR-Test, a blood test for lung cancer early detection. J. Natl. Cancer Inst. 2015, 107, djv063. [CrossRef]

49. Shen, J.; Liu, Z.; Todd, N.W.; Zhang, H.; Liao, J.; Yu, L.; Guarnera, M.A.; Li, R.; Cai, L.; Zhan, M.; et al. Diagnosis of lung cancer in individuals with solitary pulmonary nodules by plasma microRNA biomarkers. BMC Cancer 2011, 11, 374. [CrossRef]

50. Ma, J.; Li, N.; Guarnera, M.; Jiang, F. Quantification of Plasma miRNAs by Digital PCR for Cancer Diagnosis. Biomark. Insights 2013, 8, 127-136. [CrossRef] [PubMed]

51. Mozzoni, P.; Banda, I.; Goldoni, M.; Corradi, M.; Tiseo, M.; Acampa, O.; Balestra, V.; Ampollini, L.; Casalini, A.; Carbognani, P.; et al. Plasma and EBC microRNAs as early biomarkers of non-small-cell lung cancer. Biomarkers 2013, 18, 679-686. [CrossRef]

52. Tang, D.; Shen, Y.; Wang, M.; Yang, R.; Wang, Z.; Sui, A.; Jiao, W.; Wang, Y. Identification of plasma microRNAs as novel noninvasive biomarkers for early detection of lung cancer. Eur. J. Cancer Prev. 2013, 22, 540-548. [CrossRef]

53. Wang, Y.; Yi, J.; Chen, X.; Zhang, Y.; Xu, M.; Yang, Z. The regulation of cancer cell migration by lung cancer cell-derived exosomes through TGF- $\beta$ and IL-10. Oncol. Lett. 2016, 11, 1527-1530. [CrossRef]

54. Zhang, H.; Mao, F.; Shen, T.; Luo, Q.; Ding, Z.; Qian, L.; Huang, J. Plasma miR-145.; miR-20a.; miR-21 and miR-223 as novel biomarkers for screening early-stage non-small cell lung cancer. Oncol. Lett. 2017, 13, 669-676. [CrossRef] [PubMed]

55. Zhou, X.; Wen, W.; Shan, X.; Zhu, W.; Xu, J.; Guo, R.; Cheng, W.; Wang, F.; Qi, L.W.; Chen, Y.; et al. A six-microRNA panel in plasma was identified as a potential biomarker for lung adenocarcinoma diagnosis. Oncotarget 2017, 8, 6513-6525. [CrossRef]

56. Hennessey, P.T.; Sanford, T.; Choudhary, A.; Mydlarz, W.W.; Brown, D.; Adai, A.T.; Ochs, M.F.; Ahrendt, S.A.; Mambo, E.; Califano, J.A. Serum microRNA biomarkers for detection of non-small cell lung cancer. PLoS ONE 2012, 7, e32307. [CrossRef]

57. Nadal, E.; Truini, A.; Nakata, A.; Lin, J.; Reddy, R.M.; Chang, A.C.; Ramnath, N.; Gotoh, N.; Beer, D.G.; Chen, G. A Novel Serum 4-microRNA Signature for Lung Cancer Detection. Sci. Rep. 2015, 5, 12464. [CrossRef]

58. Wang, C.; Ding, M.; Xia, M.; Chen, S.; Van Le, A.; Soto-Gil, R.; Shen, Y.; Wang, N.; Wang, J.; Gu, W.; et al. A Five-miRNA Panel Identified From a Multicentric Case-control Study Serves as a Novel Diagnostic Tool for Ethnically Diverse Non-small-cell Lung Cancer Patients. EBioMedicine 2015, 2, 1377-1385. [CrossRef]

59. Yang, J.S.; Li, B.J.; Lu, H.W.; Chen, Y.; Lu, C.; Zhu, R.X.; Liu, S.H.; Yi, Q.T.; Li, J.; Song, C.H. Serum miR-152.; miR-148a.; miR-148b.; and miR-21 as novel biomarkers in non-small cell lung cancer screening. Tumour. Biol. 2015, 36, 3035-3042. [CrossRef]

60. Fan, L.; Qi, H.; Teng, J.; Su, B.; Chen, H.; Wang, C.; Xia, Q. Identification of serum miRNAs by nano-quantum dots microarray as diagnostic biomarkers for early detection of non-small cell lung cancer. Tumour. Biol. 2016, 37, 7777-7784. [CrossRef] [PubMed]

61. Halvorsen, A.R.; Bjaanæs, M.; LeBlanc, M.; Holm, A.M.; Bolstad, N.; Rubio, L.; Peñalver, J.C.; Cervera, J.; Mojarrieta, J.C.; López-Guerrero, J.A.; et al. A unique set of 6 circulating microRNAs for early detection of non-small cell lung cancer. Oncotarget 2016, 7, 37250-37259. [CrossRef] [PubMed]

62. Yang, X.; Su, W.; Chen, X.; Geng, Q.; Zhai, J.; Shan, H.; Guo, C.; Wang, Z.; Fu, H.; Jiang, H.; et al. Validation of a serum 4-microRNA signature for the detection of lung cancer. Transl. Lung Cancer Res. 2019, 8, 636-648. [CrossRef]

63. Asakura, K.; Kadota, T.; Matsuzaki, J.; Yoshida, Y.; Yamamoto, Y.; Nakagawa, K.; Takizawa, S.; Aoki, Y.; Nakamura, E.; Miura, J.; et al. A miRNA-based diagnostic model predicts resectable lung cancer in humans with high accuracy. Commun. Biol. 2020, 3, 134. [CrossRef] [PubMed]

64. Pegtel, D.M.; Gould, S.J. Exosomes. Annu. Rev. Biochem. 2019, 88, 487-514. [CrossRef]

65. Kalluri, R.; LeBleu, V.S. The biology, function, and biomedical applications of exosomes. Science 2020, 367, eaau6977. [CrossRef]

66. Kalluri, R. The biology and function of exosomes in cancer. J. Clin. Investig. 2016, 126, 1208-1215. [CrossRef]

67. Zhang, L.; Yu, D. Exosomes in cancer development, metastasis, and immunity. Biochim. Biophys. Acta Rev. Cancer 2019, 1871, 455-468. [CrossRef]

68. Whiteside, T.L. The effect of tumor-derived exosomes on immune regulation and cancer immunotherapy. Future Oncol. 2017, 13, 2583-2592. [CrossRef]

69. Kim, D.H.; Kim, H.; Choi, Y.J.; Kim, S.Y.; Lee, J.E.; Sung, K.J.; Sung, Y.H.; Pack, C.G.; Jung, M.K.; Han, B.; et al. Exosomal PD-L1 promotes tumor growth through immune escape in non-small cell lung cancer. Exp. Mol. Med. 2019, 51, 1-13. [CrossRef] [PubMed]

70. Alipoor, S.D.; Mortaz, E.; Varahram, M.; Movassaghi, M.; Kraneveld, A.D.; Garssen, J.; Adcock, I.M. The Potential Biomarkers and Immunological Effects of Tumor-Derived Exosomes in Lung Cancer. Front. Immunol. 2018, 9, 819. [CrossRef]

71. Meng, X.; Jinchang, P.; Shifang, S.; Zhaohui, G. Circulating exosomes and their cargos in blood as novel biomarkers for cancer. Transl. Cancer Res. 2018, 7, 1. [CrossRef]

72. Whiteside, T.L. The potential of tumor-derived exosomes for noninvasive cancer monitoring, an update. Expert. Rev. Mol. Diagn. 2018, 18, 1029-1040. [CrossRef] [PubMed]

73. Zheng, H.; Zhan, Y.; Liu, S.; Lu, J.; Luo, J.; Feng, J.; Fan, S. The roles of tumor-derived exosomes in non-small cell lung cancer and their clinical implications. J. Exp. Clin. Cancer Res. 2018, 37, 226. [CrossRef]

74. Liu, S.; Zhan, Y.; Luo, J.; Feng, J.; Lu, J.; Zheng, H.; Wen, Q.; Fan, S. Roles of exosomes in the carcinogenesis and clinical therapy of non-small cell lung cancer. Biomed. Pharmacother. 2019, 111, 338-346. [CrossRef] [PubMed]

75. Li, Z.; Zeng, C.; Nong, Q.; Long, F.; Liu, J.; Mu, Z.; Chen, B.; Wu, D.; Wu, H. Exosomal Leucine-Rich-Alpha2-Glycoprotein 1 Derived from Non-Small-Cell Lung Cancer Cells Promotes Angiogenesis via TGF- $\beta$ Signal Pathway. Mol. Ther. Oncolytics 2019, 14, 313-322. [CrossRef] 
76. Harada, T.; Yamamoto, H.; Kishida, S.; Kishida, M.; Awada, C.; Takao, T.; Kikuchi, A. Wnt5b-associated exosomes promote cancer cell migration and proliferation. Cancer Sci. 2017, 108, 42-52. [CrossRef] [PubMed]

77. Baig, M.S.; Roy, A.; Rajpoot, S.; Liu, D.; Savai, R.; Banerjee, S.; Kawada, M.; Faisal, S.M.; Saluja, R.; Saqib, U.; et al. Tumor-derived exosomes in the regulation of macrophage polarization. Inflamm. Res. 2020, 69, 435-451. [CrossRef]

78. Dong, C.; Liu, X.; Wang, H.; Li, J.; Dai, L.; Li, J.; Xu, Z. Hypoxic non-small-cell lung cancer cell-derived exosomal miR-21 promotes resistance of normoxic cell to cisplatin. Oncol. Targets Ther. 2019, 12, 1947-1956. [CrossRef] [PubMed]

79. Chen, R.; Xu, X.; Qian, Z.; Zhang, C.; Niu, Y.; Wang, Z.; Sun, J.; Zhang, X.; Yu, Y. The biological functions and clinical applications of exosomes in lung cancer. Cell. Mol. Life Sci. 2019, 76, 4613-4633. [CrossRef]

80. Li, Y.; Yin, Z.; Fan, J.; Zhang, S.; Yang, W. The roles of exosomal miRNAs and lncRNAs in lung diseases. Signal Transduct. Target. Ther. 2019, 4, 47. [CrossRef]

81. Fan, J.; Xu, G.; Chang, Z.; Zhu, L.; Yao, J. miR-210 transferred by lung cancer cell-derived exosomes may act as proangiogenic factor in cancer-associated fibroblasts by modulating JAK2/STAT3 pathway. Clin. Sci. 2020, 134, 807-825. [CrossRef]

82. Yuwen, D.L.; Sheng, B.B.; Liu, J.; Wenyu, W.; Shu, Y.Q. MiR-146a-5p level in serum exosomes predicts therapeutic effect of cisplatin in non-small cell lung cancer. Eur. Rev. Med. Pharmacol. Sci. 2017, 21, 2650-2658.

83. Sun, T.; Kalionis, B.; Lv, G.; Xia, S.; Gao, W. Role of Exosomal Noncoding RNAs in Lung Carcinogenesis. Biomed. Res. Int. 2015, 2015, 125807. [CrossRef] [PubMed]

84. Zhang, R.; Xia, Y.; Wang, Z.; Zheng, J.; Chen, Y.; Li, X.; Wang, Y.; Ming, H. Serum long non coding RNA MALAT-1 protected by exosomes is up-regulated and promotes cell proliferation and migration in non-small cell lung cancer. Biochem. Biophys. Res. Commun. 2017, 490, 406-414. [CrossRef] [PubMed]

85. Reclusa, P.; Taverna, S.; Pucci, M.; Durendez, E.; Calabuig, S.; Manca, P.; Serrano, M.J.; Sober, L.; Pauwels, P.; Russo, A.; et al. Exosomes as diagnostic and predictive biomarkers in lung cancer. J. Thorac. Dis. 2017, 9, S1373-S1382. [CrossRef]

86. Cui, S.; Cheng, Z.; Qin, W.; Jiang, L. Exosomes as a liquid biopsy for lung cancer. Lung Cancer 2018, 116, 46-54. [CrossRef] [PubMed]

87. Zheng, H.; Wu, X.; Yin, J.; Wang, S.; Li, Z.; You, C. Clinical applications of liquid biopsies for early lung cancer detection. Am. J. Cancer Res. 2019, 9, 2567-2579.

88. Théry, C.; Witwer, K.W.; Aikawa, E.; Alcaraz, M.J.; Anderson, J.D.; Andriantsitohaina, R.; Antoniou, A.; Arab, T.; Archer, F.; Atkin-Smith, G.K.; et al. Minimal information for studies of extracellular vesicles 2018 (MISEV2018), a position statement of the International Society for Extracellular Vesicles and update of the MISEV2014 guidelines. J. Extracell. Vesicles 2018, 7, 1535750. [CrossRef]

89. Theodoraki, M.N.; Hoffmann, T.K.; Whiteside, T.L. Separation of plasma-derived exosomes into CD3(+) and CD3(-) fractions allows for association of immune cell and tumour cell markers with disease activity in HNSCC patients. Clin. Exp. Immunol. 2018, 192, 271-283. [CrossRef]

90. Taylor, D.D.; Shah, S. Methods of isolating extracellular vesicles impact down-stream analyses of their cargoes. Methods 2015, 87, 3-10. [CrossRef]

91. Melo, S.A.; Luecke, L.B.; Kahlert, C.; Fernandez, A.F.; Gammon, S.T.; Kaye, J.; LeBleu, V.S.; Mittendorf, E.A.; Weitz, J.; Rahbari, N.; et al. Glypican-1 identifies cancer exosomes and detects early pancreatic cancer. Nature 2015, 523, 177-182. [CrossRef]

92. Turay, D.; Khan, S.; Diaz Osterman, C.J.; Curtis, M.P.; Khaira, B.; Neidigh, J.W.; Mirshahidi, S.; Casiano, C.A.; Wall, N.R. Proteomic Profiling of Serum-Derived Exosomes from Ethnically Diverse Prostate Cancer Patients. Cancer Investig. 2016, 34, 1-11. [CrossRef] [PubMed]

93. Arbelaiz, A.; Azkargorta, M.; Krawczyk, M.; Santos-Laso, A.; Lapitz, A.; Perugorria, M.J.; Erice, O.; Gonzalez, E.; JimenezAgüero, R.; Lacasta, A.; et al. Serum extracellular vesicles contain protein biomarkers for primary sclerosing cholangitis and cholangiocarcinoma. Hepatology 2017, 66, 1125-1143. [CrossRef]

94. Fang, S.; Tian, H.; Li, X.; Jin, D.; Li, X.; Kong, J.; Yang, C.; Yang, X.; Lu, Y.; Luo, Y.; et al. Clinical application of a microfluidic chip for immunocapture and quantification of circulating exosomes to assist breast cancer diagnosis and molecular classification. PLoS ONE 2017, 12, e0175050. [CrossRef]

95. Meng, X.; Müller, V.; Milde-Langosch, K.; Trillsch, F.; Pantel, K.; Schwarzenbach, H. Diagnostic and prognostic relevance of circulating exosomal miR-373.; miR-200a.; miR-200b and miR-200c in patients with epithelial ovarian cancer. Oncotarget 2016, 7, 16923-16935. [CrossRef]

96. Zlotogorski-Hurvitz, A.; Dayan, D.; Chaushu, G.; Salo, T.; Vered, M. Morphological and molecular features of oral fluid-derived exosomes, oral cancer patients versus healthy individuals. J. Cancer Res. Clin. Oncol. 2016, 142, 101-110. [CrossRef]

97. Santarpia, M.; Liguori, A.; D’Aveni, A.; Karachaliou, N.; Gonzalez-Cao, M.; Daffinà, M.G.; Lazzari, C.; Altavilla, G.; Rosell, R. Liquid biopsy for lung cancer early detection. J. Thorac. Dis. 2018, 10, S882-S897. [CrossRef]

98. Taverna, S.; Giallombardo, M.; Gil-Bazo, I.; Carreca, A.P.; Castiglia, M.; Chacártegui, J.; Araujo, A.; Alessandro, R.; Pauwels, P.; Peeters, M.; et al. Exosomes isolation and characterization in serum is feasible in non-small cell lung cancer patients, critical analysis of evidence and potential role in clinical practice. Oncotarget 2016, 7, 28748-28760. [CrossRef]

99. Sun, Y.; Liu, S.; Qiao, Z.; Shang, Z.; Xia, Z.; Niu, X.; Qian, L.; Zhang, Y.; Fan, L.; Cao, C.X.; et al. Systematic comparison of exosomal proteomes from human saliva and serum for the detection of lung cancer. Anal. Chim. Acta 2017, 982, 84-95. [CrossRef]

100. Fortunato, O.; Gasparini, P.; Boeri, M.; Sozzi, G. Exo-miRNAs as a New Tool for Liquid Biopsy in Lung Cancer. Cancers 2019, 11, 888. [CrossRef] 
101. Srivastava, A.; Amreddy, N.; Razaq, M.; Towner, R.; Zhao, Y.D.; Ahmed, R.A.; Munshi, A.; Ramesh, R. Exosomes as Theranostics for Lung Cancer. Adv. Cancer Res. 2018, 139, 1-33. [CrossRef] [PubMed]

102. Cao, B.; Wang, P.; Gu, L.; Liu, J. Use of four genes in exosomes as biomarkers for the identification of lung adenocarcinoma and lung squamous cell carcinoma. Oncol. Lett. 2021, 21, 249. [CrossRef]

103. Sandfeld-Paulsen, B.; Jakobsen, K.R.; Bæk, R.; Folkersen, B.H.; Rasmussen, T.R.; Meldgaard, P.; Varming, K.; Jørgensen, M.M.; Sorensen, B.S. Exosomal Proteins as Diagnostic Biomarkers in Lung Cancer. J. Thorac. Oncol. 2016, 11, 1701-1710. [CrossRef] [PubMed]

104. Niu, L.; Song, X.; Wang, N.; Xue, L.; Song, X.; Xie, L. Tumor-derived exosomal proteins as diagnostic biomarkers in non-small cell lung cancer. Cancer Sci. 2019, 110, 433-442. [CrossRef]

105. Ueda, K.; Ishikawa, N.; Tatsuguchi, A.; Saichi, N.; Fujii, R.; Nakagawa, H. Antibody-coupled monolithic silica microtips for highthroughput molecular profiling of circulating exosomes. Sci. Rep. 2014, 4, 6232. [CrossRef] [PubMed]

106. Vykoukal, J.; Sun, N.; Aguilar-Bonavides, C.; Katayama, H.; Tanaka, I.; Fahrmann, J.F.; Capello, M.; Fujimoto, J.; Aguilar, M.; Wistuba, I.I.; et al. Plasma-derived extracellular vesicle proteins as a source of biomarkers for lung adenocarcinoma. Oncotarget 2017, 8, 95466-95480. [CrossRef] [PubMed]

107. Wang, N.; Song, X.; Liu, L.; Niu, L.; Wang, X.; Song, X.; Xie, L. Circulating exosomes contain protein biomarkers of metastatic non-small-cell lung cancer. Cancer Sci. 2018, 109, 1701-1709. [CrossRef] [PubMed]

108. Tao, Y.; Tang, Y.; Yang, Z.; Wu, F.; Wang, L.; Yang, L.; Lei, L.; Jing, Y.; Jiang, X.; Jin, H.; et al. Exploration of Serum Exosomal LncRNA TBILA and AGAP2-AS1 as Promising Biomarkers for Diagnosis of Non-Small Cell Lung Cancer. Int. J. Biol. Sci. 2020, 16, 471-482. [CrossRef]

109. Zhang, X.; Guo, H.; Bao, Y.; Yu, H.; Xie, D.; Wang, X. Exosomal long non-coding RNA DLX6-AS1 as a potential diagnostic biomarker for non-small cell lung cancer. Oncol. Lett. 2019, 18, 5197-5204. [CrossRef]

110. Li, C.; Lv, Y.; Shao, C.; Chen, C.; Zhang, T.; Wei, Y.; Fan, H.; Lv, T.; Liu, H.; Song, Y. Tumor-derived exosomal lncRNA GAS5 as a biomarker for early-stage non-small-cell lung cancer diagnosis. J. Cell. Physiol. 2019, 234, 20721-20727. [CrossRef] [PubMed]

111. Wang, J.; Zhao, X.; Wang, Y.; Ren, F.; Sun, D.; Yan, Y.; Kong, X.; Bu, J.; Liu, M.; Xu, S. circRNA-002178 act as a ceRNA to promote PDL1/PD1 expression in lung adenocarcinoma. Cell Death Dis. 2020, 11, 32. [CrossRef]

112. Fan, T.W.M.; Zhang, X.; Wang, C.; Yang, Y.; Kang, W.Y.; Arnold, S.; Higashi, R.M.; Liu, J.; Lane, A.N. Exosomal lipids for classifying early and late stage non-small cell lung cancer. Anal. Chim. Acta 2018, 1037, 256-264. [CrossRef]

113. Cazzoli, R.; Buttitta, F.; Di Nicola, M.; Malatesta, S.; Marchetti, A.; Rom, W.N.; Pass, H.I. microRNAs derived from circulating exosomes as noninvasive biomarkers for screening and diagnosing lung cancer. J. Thorac. Oncol. 2013, 8, 1156-1162. [CrossRef]

114. Giallombardo, M.; Chacártegui, B.J.; Castiglia, M.; Van Der Steen, N.; Mertens, I.; Pauwels, P.; Peeters, M.; Rolfo, C. Exosomal miRNA Analysis in Non-small Cell Lung Cancer (NSCLC) Patients' Plasma Through qPCR, A Feasible Liquid Biopsy Tool. J. Vis. Exp. 2016, 111, 53900. [CrossRef] [PubMed]

115. Liu, Q.; Yu, Z.; Yuan, S.; Xie, W.; Li, C.; Hu, Z.; Xiang, Y.; Wu, N.; Wu, L.; Bai, L.; et al. Circulating exosomal microRNAs as prognostic biomarkers for non-small-cell lung cancer. Oncotarget 2017, 8, 13048-13058. [CrossRef]

116. Zhang, J.T.; Qin, H.; Man Cheung, F.K.; Su, J.; Zhang, D.D.; Liu, S.Y.; Li, X.F.; Qin, J.; Lin, J.T.; Jiang, B.Y.; et al. Plasma extracellular vesicle microRNAs for pulmonary ground-glass nodules. J. Extracell. Vesicles 2019, 8, 1663666. [CrossRef] [PubMed]

117. Rabinowits, G.; Gerçel-Taylor, C.; Day, J.M.; Taylor, D.D.; Kloecker, G.H. Exosomal microRNA, a diagnostic marker for lung cancer. Clin. Lung Cancer 2009, 10, 42-46. [CrossRef]

118. Silva, J.; García, V.; Zaballos, Á.; Provencio, M.; Lombardía, L.; Almonacid, L.; García, J.M.; Domínguez, G.; Peña, C.; Diaz, R.; et al. Vesicle-related microRNAs in plasma of nonsmall cell lung cancer patients and correlation with survival. Eur. Respir. J. 2011, 37, 617-623. [CrossRef]

119. Jin, X.; Chen, Y.; Chen, H.; Fei, S.; Chen, D.; Cai, X.; Liu, L.; Lin, B.; Su, H.; Zhao, L.; et al. Evaluation of Tumor-Derived Exosomal miRNA as Potential Diagnostic Biomarkers for Early-Stage Non-Small Cell Lung Cancer Using Next-Generation Sequencing. Clin. Cancer Res. 2017, 23, 5311-5319. [CrossRef] [PubMed]

120. Dejima, H.; Iinuma, H.; Kanaoka, R.; Matsutani, N.; Kawamura, M. Exosomal microRNA in plasma as a non-invasive biomarker for the recurrence of non-small cell lung cancer. Oncol. Lett. 2017, 13, 1256-1263. [CrossRef] [PubMed]

121. Nigita, G.; Distefano, R.; Veneziano, D.; Romano, G.; Rahman, M.; Wang, K.; Pass, H.; Croce, C.M.; Acunzo, M.; Nana-Sinkam, P. Tissue and exosomal miRNA editing in Non-Small Cell Lung Cancer. Sci. Rep. 2018, 8, 10222. [CrossRef]

122. Poroyko, V.; Mirzapoiazova, T.; Nam, A.; Mambetsariev, I.; Mambetsariev, B.; Wu, X.; Husain, A.; Vokes, E.E.; Wheeler, D.L.; Salgia, R. Exosomal miRNAs species in the blood of small cell and non-small cell lung cancer patients. Oncotarget 2018, 9, 19793-19806. [CrossRef]

123. Zhang, Y.; Yin, Y.; Li, S. Detection of circulating exosomal miR-17-5p serves as a novel non-invasive diagnostic marker for non-small cell lung cancer patients. Pathol. Res. Pract. 2019, 215, 152466. [CrossRef]

124. Wu, Q.; Yu, L.; Lin, X.; Zheng, Q.; Zhang, S.; Chen, D.; Pan, X.; Huang, Y. Combination of Serum miRNAs with Serum Exosomal miRNAs in Early Diagnosis for Non-Small-Cell Lung Cancer. Cancer Manag. Res. 2020, 12, 485-495. [CrossRef]

125. Liu, W.; Liu, J.; Zhang, Q.; Wei, L. Downregulation of serum exosomal miR-216b predicts unfavorable prognosis in patients with non-small cell lung cancer. Cancer Biomark. 2020, 27, 113-120. [CrossRef]

126. Sun, S.; Chen, H.; Xu, C.; Zhang, Y.; Zhang, Q.; Chen, L.; Ding, Q.; Deng, Z. Exosomal miR-106b serves as a novel marker for lung cancer and promotes cancer metastasis via targeting PTEN. Life Sci. 2020, 244, 117297. [CrossRef] [PubMed] 
127. Zhang, L.; Shan, X.; Wang, J.; Zhu, J.; Huang, Z.; Zhang, H.; Zhou, X.; Cheng, W.; Shu, Y.; Zhu, W.; et al. A three-microRNA signature for lung squamous cell carcinoma diagnosis in Chinese male patients. Oncotarget 2017, 8, 86897-86907. [CrossRef] [PubMed]

128. Wang, X.; Jiang, X.; Li, J.; Wang, J.; Binang, H.; Shi, S.; Duan, W.; Zhao, Y.; Zhang, Y. Serum exosomal miR-1269a serves as a diagnostic marker and plays an oncogenic role in non-small cell lung cancer. Thorac. Cancer 2020, 11, 3436-3447. [CrossRef] [PubMed]

129. Wu, Y.; Wei, J.; Zhang, W.; Xie, M.; Wang, X.; Xu, J. Serum Exosomal miR-1290 is a Potential Biomarker for Lung Adenocarcinoma. Oncol. Targets Ther. 2020, 13, 7809-7818. [CrossRef] [PubMed]

130. Zhang, Y.; Xu, H. Serum exosomal miR-378 upregulation is associated with poor prognosis in non-small-cell lung cancer patients. J. Clin. Lab. Anal. 2020, 34, e23237. [CrossRef]

131. Chen, L.; Cao, P.; Huang, C.; Wu, Q.; Chen, S.; Chen, F. Serum exosomal miR-7977 as a novel biomarker for lung adenocarcinoma. J. Cell. Biochem. 2020, 121, 3382-3391. [CrossRef]

132. Grimolizzi, F.; Monaco, F.; Leoni, F.; Bracci, M.; Staffolani, S.; Bersaglieri, C.; Gaetani, S.; Valentino, M.; Amati, M.; Rubini, C.; et al. Exosomal miR-126 as a circulating biomarker in non-small-cell lung cancer regulating cancer progression. Sci. Rep. 2017, 7, 15277. [CrossRef]

133. Feng, M.; Zhao, J.; Wang, L.; Liu, J. Upregulated Expression of Serum Exosomal microRNAs as Diagnostic Biomarkers of Lung Adenocarcinoma. Ann. Clin. Lab. Sci. 2018, 48, 712-718. [PubMed]

134. Tang, Y.; Zhang, Z.; Song, X.; Yu, M.; Niu, L.; Zhao, Y.; Wang, L.; Song, X.; Xie, L. Tumor-Derived Exosomal miR-620 as a Diagnostic Biomarker in Non-Small-Cell Lung Cancer. J. Oncol. 2020, 2020, 6691211. [CrossRef]

135. Zhang, Z.; Tang, Y.; Song, X.; Xie, L.; Zhao, S.; Song, X. Tumor-Derived Exosomal miRNAs as Diagnostic Biomarkers in Non-Small Cell Lung Cancer. Front. Oncol. 2020, 10, 560025. [CrossRef] [PubMed]

136. Zhang, Z.J.; Song, X.G.; Xie, L.; Wang, K.Y.; Tang, Y.Y.; Yu, M.; Feng, X.D.; Song, X.R. Circulating serum exosomal miR-20b-5p and miR-3187-5p as efficient diagnostic biomarkers for early-stage non-small cell lung cancer. Exp. Biol. Med. 2020, 245, 1428-1436. [CrossRef] [PubMed]

137. Olive, V.; Li, Q.; He, L. mir-17-92, a polycistronic oncomir with pleiotropic functions. Immunol. Rev. 2013, 253, 158-166. [CrossRef] [PubMed]

138. Ventura, A.; Young, A.G.; Winslow, M.M.; Lintault, L.; Meissner, A.; Erkeland, S.J.; Newman, J.; Bronson, R.T.; Crowley, D.; Stone, J.R.; et al. Targeted deletion reveals essential and overlapping functions of the miR-17 through 92 family of miRNA clusters. Cell 2008, 132, 875-886. [CrossRef]

139. Mogilyansky, E.; Rigoutsos, I. The miR-17/92 cluster, a comprehensive update on its genomics; genetics; functions and increasingly important and numerous roles in health and disease. Cell Death Differ. 2013, 20, 1603-1614. [CrossRef]

140. Zhang, X.; Li, Y.; Qi, P.; Ma, Z. Biology of MiR-17-92 Cluster and Its Progress in Lung Cancer. Int. J. Med. Sci. 2018, 15, 1443-1448. [CrossRef]

141. Feng, Y.H.; Tsao, C.J. Emerging role of microRNA-21 in cancer. Biomed. Rep. 2016, 5, 395-402. [CrossRef]

142. Bica-Pop, C.; Cojocneanu-Petric, R.; Magdo, L.; Raduly, L.; Gulei, D.; Berindan-Neagoe, I. Overview upon miR-21 in lung cancer, focus on NSCLC. Cell. Mol. Life Sci. 2018, 75, 3539-3551. [CrossRef]

143. Zhou, B.; Wang, D.; Sun, G.; Mei, F.; Cui, Y.; Xu, H. Effect of miR-21 on Apoptosis in Lung Cancer Cell Through Inhibiting the PI3K/Akt/NF-kB Signaling Pathway in Vitro and in Vivo. Cell. Physiol. Biochem. 2018, 46, 999-1008. [CrossRef]

144. Marin, I.; Ofek, E.; Bar, J.; Prisant, N.; Perelman, M.; Avivi, C.; Lavy-Shahaf, G.; Onn, A.; Katz, R.; Barshack, I. MiR-21.; EGFR and PTEN in non-small cell lung cancer, an in situ hybridisation and immunohistochemistry study. J. Clin. Pathol. 2020, 73, 636-641. [CrossRef] [PubMed]

145. Yin, G.; Zhang, B.; Li, J. miR-221-3p promotes the cell growth of non-small cell lung cancer by targeting p27. Mol. Med. Rep. 2019, 20, 604-612. [CrossRef] [PubMed]

146. Zheng, J.; Dong, L.; Hu, X.; Xiao, Y.; Wu, Q.; Wang, Y.; Zhu, Y. MicroRNA-221-3p promotes proliferation and invasion in non-small cell lung cancer via targeting Axin2 to regulate Wnt/ $\beta$-catenin signaling pathway. Res. Sq. 2020, 1, 1-20. [CrossRef]

147. He, R.Q.; Cen, W.L.; Cen, J.M.; Cen, W.N.; Li, J.Y.; Li, M.W.; Gan, T.Q.; Hu, X.H.; Chen, G. Clinical Significance of miR-210 and its Prospective Signaling Pathways in Non-Small Cell Lung Cancer: Evidence from Gene Expression Omnibus and the Cancer Genome Atlas Data Mining with 2763 Samples and Validation via Real-Time Quantitative PCR. Cell. Physiol. Biochem. 2018, 46, 925-952. [CrossRef]

148. Ju, S.; Liang, Z.; Li, C.; Ding, C.; Xu, C.; Song, X.; Zhao, J. The effect and mechanism of miR-210 in down-regulating the autophagy of lung cancer cells. Pathol. Res. Pract. 2019, 215, 453-458. [CrossRef] [PubMed]

149. Goto, A.; Tanaka, M.; Yoshida, M.; Umakoshi, M.; Nanjo, H.; Shiraishi, K.; Saito, M.; Kohno, T.; Kuriyama, S.; Konno, H.; et al. The low expression of miR-451 predicts a worse prognosis in non-small cell lung cancer cases. PLoS ONE 2017, 12, e0181270. [CrossRef]

150. Chen, D.; Huang, J.; Zhang, K.; Pan, B.; Chen, J.; De, W.; Wang, R.; Chen, L. MicroRNA-451 induces epithelial-mesenchymal transition in docetaxel-resistant lung adenocarcinoma cells by targeting proto-oncogene c-Myc. Eur. J. Cancer 2014, 50, 3050-3067. [CrossRef] [PubMed]

151. Li, L.; Gao, R.; Yu, Y.; Kaul, Z.; Wang, J.; Kalra, R.S.; Zhang, Z.; Kaul, S.C.; Wadhwa, R. Tumor suppressor activity of miR-451, Identification of CARF as a new target. Sci. Rep. 2018, 8, 375. [CrossRef] 
152. Li, M.; Wang, Q.; Zhang, X.; Yan, N.; Li, X. Exosomal miR-126 blocks the development of non-small cell lung cancer through the inhibition of ITGA6. Cancer Cell Int. 2020, 20, 574. [CrossRef]

153. Dong, W.; Yao, C.; Teng, X.; Chai, J.; Yang, X.; Li, B. MiR-140-3p suppressed cell growth and invasion by downregulating the expression of ATP8A1 in non-small cell lung cancer. Tumour. Biol. 2016, 37, 2973-2985. [CrossRef] [PubMed]

154. Yuan, Y.; Shen, Y.; Xue, L.; Fan, H. miR-140 suppresses tumor growth and metastasis of non-small cell lung cancer by targeting insulin-like growth factor 1 receptor. PLoS ONE 2013, 8, e73604. [CrossRef]

155. Gao, Z.J.; Yuan, W.D.; Yuan, J.Q.; Yuan, K.; Wang, Y. miR-486-5p functions as an oncogene by targeting PTEN in non-small cell lung cancer. Pathol. Res. Pract. 2018, 214, 700-705. [CrossRef] [PubMed]

156. Jin, X.; Pang, W.; Zhang, Q.; Huang, H. MicroRNA-486-5p improves nonsmall-cell lung cancer chemotherapy sensitivity and inhibits epithelial-mesenchymal transition by targeting twinfilin actin binding protein 1. J. Int. Med. Res. 2019, 47, 3745-3756. [CrossRef]

157. Yu, S.; Geng, S.; Hu, Y. miR-486-5p inhibits cell proliferation and invasion through repressing GAB2 in non-small cell lung cancer. Oncol. Lett. 2018, 16, 3525-3530. [CrossRef]

158. Wang, A.; Zhu, J.; Li, J.; Du, W.; Zhang, Y.; Cai, T.; Liu, T.; Fu, Y.; Zeng, Y.; Liu, Z.; et al. Downregulation of KIAA1199 by miR-486-5p suppresses tumorigenesis in lung cancer. Cancer Med. 2020, 9, 5570-5586. [CrossRef]

159. Su, J.L.; Chen, P.S.; Johansson, G.; Kuo, M.L. Function and regulation of let-7 family microRNAs. Microrna 2012, 1, 34-39. [CrossRef] [PubMed]

160. Gilles, M.E.; Slack, F.J. Let-7 microRNA as a potential therapeutic target with implications for immunotherapy. Expert. Opin. Ther. Targets 2018, 22, 929-939. [CrossRef]

161. Chiu, S.C.; Chung, H.Y.; Cho, D.Y.; Chan, T.M.; Liu, M.C.; Huang, H.M.; Li, T.Y.; Lin, J.Y.; Chou, P.C.; Fu, R.H.; et al. Therapeutic potential of microRNA let-7, tumor suppression or impeding normal stemness. Cell Transplant. 2014, 23, 459-469. [CrossRef]

162. Sonkoly, E.; Ståhle, M.; Pivarcsi, A. MicroRNAs and immunity, novel players in the regulation of normal immune function and inflammation. Semin. Cancer Biol. 2008, 18, 131-140. [CrossRef]

163. Liu, X.; Liu, B.; Li, R.; Wang, F.; Wang, N.; Zhang, M.; Bai, Y.; Wu, J.; Liu, L.; Han, D.; et al. miR-146a-5p Plays an Oncogenic Role in NSCLC via Suppression of TRAF6. Front. Cell Dev. Biol. 2020, 8, 847. [CrossRef]

164. Sun, X.; Cui, S.; Fu, X.; Liu, C.; Wang, Z.; Liu, Y. MicroRNA-146-5p promotes proliferation.; migration and invasion in lung cancer cells by targeting claudin-12. Cancer Biomark. 2019, 25, 89-99. [CrossRef]

165. Li, Y.; Tian, J.; Guo, Z.J.; Zhang, Z.B.; Xiao, C.Y.; Wang, X.C. Expression of microRNAs-106b in nonsmall cell lung cancer. J. Cancer Res. Ther. 2018, 14, S295-S298. [CrossRef]

166. Wei, K.; Pan, C.; Yao, G.; Liu, B.; Ma, T.; Xia, Y.; Jiang, W.; Chen, L.; Chen, Y. MiR-106b-5p Promotes Proliferation and Inhibits Apoptosis by Regulating BTG3 in Non-Small Cell Lung Cancer. Cell. Physiol. Biochem. 2017, 44, 1545-1558. [CrossRef]

167. Ren, T.; Fan, X.X.; Wang, M.F.; Duan, F.G.; Wei, C.L.; Li, R.Z.; Jiang, Z.B.; Wang, Y.W.; Yao, X.J.; Chen, M.W.; et al. miR-20b promotes growth of non-small cell lung cancer through a positive feedback loop of the Wnt/ $\beta$-catenin signaling pathway. Int. J. Oncol. 2020, 56, 470-479. [CrossRef]

168. Peng, L.; Li, S.; Li, Y.; Wan, M.; Fang, X.; Zhao, Y.; Zuo, W.; Long, D.; Xuan, Y. Regulation of BTG3 by microRNA-20b-5p in non-small cell lung cancer. Oncol. Lett. 2019, 18, 137-144. [CrossRef]

169. Jin, J.; Deng, J.; Wang, F.; Xia, X.; Qiu, T.; Lu, W.; Li, X.; Zhang, H.; Gu, X.; Liu, Y.; et al. The expression and function of microRNA-203 in lung cancer. Tumour. Biol. 2013, 34, 349-357. [CrossRef]

170. Chi, Y.; Jin, Q.; Liu, X.; Xu, L.; He, X.; Shen, Y.; Zhou, Q.; Zhang, J.; Jin, M. miR-203 inhibits cell proliferation.; invasion.; and migration of non-small-cell lung cancer by downregulating RGS17. Cancer Sci. 2017, 108, 2366-2372. [CrossRef]

171. Wang, N.; Liang, H.; Zhou, Y.; Wang, C.; Zhang, S.; Pan, Y.; Wang, Y.; Yan, X.; Zhang, J.; Zhang, C.Y.; et al. miR-203 suppresses the proliferation and migration and promotes the apoptosis of lung cancer cells by targeting SRC. PLoS ONE 2014, 9, e105570. [CrossRef] [PubMed]

172. Huang, H.Y.; Lin, Y.C.; Li, J.; Huang, K.Y.; Shrestha, S.; Hong, H.C.; Tang, Y.; Chen, Y.G.; Jin, C.N.; Yu, Y.; et al. miRTarBase 2020: Updates to the experimentally validated microRNA-target interaction database. Nucleic Acids Res. 2020, 48, D148-D154. [CrossRef]

173. Pathan, M.; Keerthikumar, S.; Ang, C.S.; Gangoda, L.; Quek, C.Y.; Williamson, N.A.; Mouradov, D.; Sieber, O.M.; Simpson, R.J.; Salim, A.; et al. An open access standalone functional enrichment and interaction network analysis tool. Proteomics 2015, 15, 2597-2601. [CrossRef] 